\title{
Calcium Concentration Dynamics Produced by Synaptic Activation of CA1 Hippocampal Pyramidal Cells
}

\author{
Wade G. Regehr ${ }^{\mathrm{a}}$ and David W. Tank \\ Biological Computation Research Department, AT\&T Bell Laboratories, Murray Hill, New Jersey 07974
}

The spatial and temporal dynamics of many electrophysiological and biochemical processes in nerve cells are in turn dependent on the concentration dynamics of the second messenger calcium. We have used microfluorimetry of the calcium indicator fura-2 (Grynkiewicz et al., 1985) to measure and characterize synaptically activated calcium changes in individual CA1 pyramidal cells contained within guinea pig hippocampal slices.

One component of the calcium changes was largely produced by influx through voltage-dependent $\mathrm{Ca}^{2+}$ channels (VDCCs). It consisted of large transient accumulations in the proximal-apical and basal dendrites; the amplitude was smaller in the distal-apical dendrites and the soma. This spatial profile was insensitive to the method of cell activation: stimulation of inputs located at different positions on the dendritic tree as well as antidromic stimulation produced only slight modifications. This component was not blocked by the NMDA antagonist 5-amino-4-phosphonovalerate (AP5) (Collingridge et al., 1983), was greatly reduced by $\mathrm{Cd}^{2+}$, partially reduced by nifedipine, and was increased by Bay-K 8644 , providing the evidence that it was largely produced by influx through VDCCs. Blocking postsynaptic $\mathrm{Na}^{+}$channels with QX-314 greatly reduced the accumulation amplitude, and spatial differences between proximal-dendritic and distal-dendritic regions were less pronounced, suggesting that active sodium conductances contribute significantly to the spatial activation of calcium conductances. Residual spatial differences that persist in QX-314 experiments are consistent with the idea that VDCCs have decreased density on distal-apical dendrites.

A second component of accumulation was induced by ionic currents through NMDA receptor channels. It was blocked by AP5, unaffected by $Q X-314$, attenuated and slowed down by elevated calcium buffering, and spatially localized to regions receiving activated synaptic inputs. The magnitude of this component was strongly dependent on the frequency and amplitude of synaptic activation. At high frequency, it was generally very large, often saturating the fura-2 $(>2 \mu \mathrm{M})$. Measurements made with the indicator furaptra also showed large localized AP5-sensitive fluorescence changes. Our results suggest that in dendritic regions near activated input fibers calcium levels may reach 2-10 $\mu \mathrm{m}$.

\footnotetext{
Received Oct. 23, 1991; revised Apr. 29, 1992; accepted May 8, 1992.

We thank Alan Kay and Kerry Delaney for many helpful discussions.

Correspondence should be addressed to David W. Tank, Biological Computation Research Department, AT\&T Bell Laboratories, 600 Mountain Avenue, Murray Hill, NJ 07974.

a Present address: Department of Physiology, University of Pennsylvania Medical Center, Philadelphia, PA 19104.

Copyright (C) 1992 Society for Neuroscience $0270-6474 / 92 / 124202-21 \$ 05.00 / 0$
}

In general, our measurements of calcium dynamics provide an experimental basis for evaluating the spatial distribution of calcium conductances, the spatial distribution of calcium-activated electrophysiological and biochemical processes, and the spatial uniformity of calcium buffering and removal systems in CA1 hippocampal pyramidal cells. The time course and amplitude of $\mathrm{Ca}^{2+}$ transients we measured suggest that activation of $\mathrm{Ca}^{2+}$-dependent conductances [e.g., $\left.I_{k(\mathrm{Ca})}\right]$ will be markedly different for different cellular regions. The frequency dependence of the AP5-sensitive component is consistent with the $\mathrm{Ca}^{2+}$ induction model of long-term potentiation (LTP) and with ionic currents through the NMDA receptor channel serving to trigger LTP through accumulations of very large $\mathrm{Ca}^{2+}$ levels in the postsynaptic dendrite. When combined with recent results on the induction of LTP in the presence of AP5, our results suggest that the large AP5-sensitive $\mathrm{Ca}^{2+}$ accumulations are produced by both $\mathrm{Ca}^{2+}$ current through NMDA receptors and $\mathrm{Ca}^{2+}$ influx through VDCCs. The very large AP5-insensitive accumulations seen in dendritic regions that do not become potentiated during LTP suggest that either much higher $\mathrm{Ca}^{2+}$ levels (>low micromolar) are required to induce LTP, or that the spine apparatus sufficiently isolates the spine, preventing large $\mathrm{Ca}^{2+}$ accumulations in the dendrite from reaching the spine head.

Calcium ion dynamics, like membrane potential dynamics, are an important description of the interaction of complex interdependent physical processes in nerve cells. The temporal and spatial changes in membrane potential are traditionally recognized as a simplifying description of the interacting ionic current flows underlying phenomena like the action potential. Membrane potential is thus seen as a "natural" variable for the description of nerve cell electrophysiology. In mathematical terms, the membrane potential is the physical variable that "couples" the differential equations in the Hodgkin-Huxley model of electrophysiological phenomena, representing the fact that electrical potential is often the physical mechanism by which the different ionic channels interact with each other. It is increasingly clear that $\left[\mathrm{Ca}^{2+}\right]_{i}$ is another natural variable in the description of interdependent physical processes that govern nerve cell electrophysiology and biochemistry. For example, calcium ions regulate a variety of conductances (Adams et al., 1982; Eckert and Chad, 1984; Lancaster and Nicoll, 1987; Partridge and Swandula, 1988; Williamson and Alger, 1990; Kay, 1991). This has been recognized in a number of recent "Hodgkin-Huxley" models for which $\left[\mathrm{Ca}^{2+}\right]_{i}$ cross-couples the differential equations describing ionic current flow (cf. Yamada et al., 1989).

The central role of calcium ions is especially evident in syn- 
aptic plasticity and cellular biochemistry. The induction of longterm potentiation (LTP) (Bliss and Gardner-Medwin, 1973; Bliss and Lomo, 1973; Brown et al., 1988; Nicoll et al., 1988; Malenka et al., 1989; Madison et al., 1991) requires calcium increases in the postsynaptic neuron (Lynch et al., 1983). Mathematical models of synapses relevant to plasticity emphasize $\left[\mathrm{Ca}^{2+}\right]_{i}$ as a central and simplifying parameter describing the interacting physical processes (Gamble and Koch, 1987; Lisman, 1989; Holmes and Levy, 1990). Calcium may also play a role in a wide variety of other cellular processes including the activation of immediate-early genes, cell death, kindling, and epilepsy (Schwartzkroin and Prince, 1978; Traub and Llinas, 1979; Wong and Prince, 1979; Wadman et al., 1985; Choi, 1988; Scharfman and Schwartzkroin, 1989; Morgan and Curran, 1991). Just as it has been important to characterize membrane potential dynamics such as action potentials, subthreshold rhythmic oscillations, and so on, so too it is important to characterize the spatial and temporal dynamics of $\left[\mathrm{Ca}^{2+}\right]_{i}$.

In undertaking the task of characterizing synaptically activated calcium transients in hippocampal pyramidal cells, we chose to measure $\left[\mathrm{Ca}^{2+}\right]_{i}$ in individual nerve cells in mammalian brain slice using methods similar to those described by Tank et al. (1988). Cells within a brain slice have advantages over tissuecultured neurons. Synaptic circuitry is partially intact, and cell morphology and channel densities are likely to be well preserved. Such geometrical and anatomical considerations are crucially important to $\mathrm{Ca}^{2+}$ accumulations and subsequent second messenger actions. In order to obtain quantitative spatially resolved measurements of calcium, it was necessary to fill individual neurons iontophoretically with fura-2. Bulk loading cells with the membrane-permeant form of fura-2, while having been successfully used to measure $\mathrm{Ca}^{2+}$ transients in somata of pyramidal neurons contained within hippocampal slices (Kudo and Ogura, 1986; Ogura et al., 1987), was not appropriate for these studies. Although technically easy, bath-applied fura-2 acetoxymethyl ester loading is unreliable in adult brain slice (Regehr and Tank, 1991; Yuste and Katz, 1989) and does not provide control over which elements in the slice are loaded. Pyramidal cells, non-neuronal cells, interneurons, and presynaptic structures would all contribute to the fura- 2 fluorescence signal, making anything but somatic calcium measurements difficult to interpret.

We have previously demonstrated that by iontophoretically injecting fura-2 into individual neurons within hippocampal slices, $\left[\mathrm{Ca}^{2+}\right]$, changes in pyramidal cell dendrites can be measured (Regehr et al., 1989; Regehr and Tank, 1990a). These studies raised a number of questions concerning calcium accumulations produced by synaptic activation. What is the source of calcium for these transients? How do the stimulus intensity and frequency and the location of synaptic inputs affect the magnitude and spatial distribution of the accumulations? What is the cffect of the addition of exogenous calcium buffer? Here, we extend our previous studies to further characterize calcium accumulations produced by synaptic activation.

Portions of the material presented here have appeared in abstract form elsewhere (Regehr and Tank, 1990b).

\section{Materials and Methods}

Brain slice electrophysiology. Brain slice preparation and maintenance followed standard procedures (Yamamoto, 1972; Schwartzkroin, 1975). Transverse $300-\mu \mathrm{m}$-thick hippocampal slices from guinea pigs (125-
$300 \mathrm{gm}$ ) were cut on a vibratome (Ted Pella DTX-1000 microslicer). Control saline consisted of (in $\mathrm{mm}$ ) $124 \mathrm{NaCl}, 5 \mathrm{KCl}, 2 \mathrm{CaCl}_{2}, 1.6$ $\mathrm{MgCl}_{2}, 26 \mathrm{NaHCO}_{3}$, and $10 \mathrm{~d}$-glucose. For experiments using picrotoxin (PTX), the divalent ion concentration was raised to $4 \mathrm{mM} \mathrm{Ca}^{2+}$ and 4 $\mathrm{mM} \mathrm{Mg}^{2+}$ to minimize epileptiform activity. Slices were placed on the bottom (\#1 glass coverslip) of a Plexiglas submersion chamber $(1.5 \mathrm{ml}$ vol; flow rate, approximately $2 \mathrm{ml} / \mathrm{min}$ ) and held in position using gold electron microscope grids (Ted Pella 19912H). The chamber was mounted on a copper plate, and saline temperature was maintained at 30$32^{\circ} \mathrm{C}$ with a Peltier device (Camcool Modules). This unit was attached to the stage of an inverted microscope (Zeiss IM35) fitted with a dissecting scope (Zeiss SV8) in place of the condenser assembly to allow vicwing of the slice from above. Cells were filled with fura-2 (Molecular Probes, Eugene, OR) using fine-tipped intracellular electrodes and a stage-mounted hydraulic manipulator (Narishige, MO-203). The electrodes (AM Systems 6010) were pulled on a Flaming-Brown micropipette puller (Sutter Instruments model P80) and had an impedance of $150-250 \mathrm{M} \Omega$

Fura- 2 was prepared by dissolving $1 \mathrm{mg}$ of the pentapotassium salt in $20 \mu \mathrm{l}$ of $5 \mathrm{~mm} \mathrm{KOH}$. This stock solution was aliquotted and stored frozen in a light-tight container for up to 1 month. Aliquots were diluted 4:1 with a solution containing $50 \mathrm{~mm} \mathrm{~K}$-HEPES and $50 \mathrm{~mm}$ concentrations of either $\mathrm{K}$-acetate or $\mathrm{KCl}(\mathrm{pH} 7.3)$ to make a solution with a final concentration of $14 \mathrm{~mm}$ fura-2. This injection solution was stored for up to 1 week at $-20^{\circ} \mathrm{C}$. To conserve fura- 2 , only the electrode tips were backfilled with fura- 2 solution, and an $\mathrm{Ag} / \mathrm{AgCl}$ wire was inserted into the rear of the clectrode to make clectrical contact with the solution maintained along the glass fiber.

Individual pyramidal cells were iontophoretically filled with currents of $-1 \mathrm{nA}$ for 5 min using a conventional bridge amplifier (Neuro Data model IR-283). After injection, cells used in imaging experiments had membrane potentials more negative than $-50 \mathrm{mV}$ and responded to small depolarizations with an adapting burst of action potentials. Injections of fura- 2 to levels used in these experiments had small effects on cell firing properties. Filling to an estimated $100 \mu \mathrm{M}$ fura-2 produced only a slight alteration in the accommodation properties of pyramidal cells in response to a $600 \mathrm{msec}$ depolarizing current pulse. Following injection, the intracellular electrode was removed and 30-60 min allowed for the dye to diffuse and fill distal dendrites. The slice was then turned over, and a stimulus electrode(s) (bipolar metal electrode with $50 \mu \mathrm{m}$ spacing) and a glass capillary recording clectrode ( $2 \mathrm{M} \mathrm{NaCl} ; 4$ $6 \mathrm{M} \Omega$ ) were appropriately positioned, guided by cell fluorescence. The extracellular electrode was placed within $100 \mu \mathrm{m}$ of the cell soma and used to record the population spike field potential evoked by a $0.1 \mathrm{~Hz}$ test pulse (A.M.P.I. Master-8 Stimulator). Field potential recordings were amplified, filtered (model 113, Princeton Applied Research; DC $1000 \mathrm{~Hz}$ ), and stored on tape (model DR-484, Neuro Data) or captured on an oscilloscope (Tektronix 5223). Experiments conducted with 5-amino-4-phosphonovalerate (AP5)-containing saline used $100 \mu \mathrm{M} \mathrm{DL}-$ AP5 (Sigma) or 50-100 $\mu \mathrm{M}$ D-AP5 (Sigma) with 25-30 min washouts.

Calcium imaging. From comparison of the cell soma fluorescence with the fluorescence of calibration solutions of known path length and dye concentration, the intracellular fura-2 concentrations used in these experiments were estimated to be 50-150 $\mu \mathrm{M}$. Cells filled with higher levels of fura-2 showed smaller accumulations, and slower time courses (see Fig. 6 and caption). To minimize light scatter, only cells within 100 $\mu \mathrm{m}$ of the slice surface were imaged. Figure 1 is a schematic diagram of the optical system used in these experiments. The microscope was a Zeiss IM35 fitted with quartz epiillumination and telan lens, and for most experiments the objective used was a Nikon $10 \times$ Fluor $(0.5 \mathrm{NA})$. Images were acquired with a computer-controlled (MacIlfx) cooled CCD camera ( $\mathrm{CH} 220$, Photometrics, Tucson, AZ). The ratio of fura-2 fluorescence with $340 \mathrm{~nm}$ excitation to that at $380 \mathrm{~nm}$ was uniform to better than $5 \%$ over the field of view, and the intensity was uniform to $30 \%$ over the field of view.

The background fluorescence was large, making it crucial for accurate $\mathrm{Ca}^{2+}$ determination to obtain an appropriate background that could be subtracted from the cell fluorescence image leaving only the fluorescence of fura-2. The background fluorescence was minimized using the field aperture to restrict the area of illumination to about $500-700 \mu \mathrm{m} \mathrm{di}$ ameter. A background image was taken of an area of the slice near the cell to be imaged (slightly defocused to minimize the effects of small scale nonuniformities). This background image was subtracted from subsequent images of the cell. To assess the relative intensity of background fluorescence, the fluorescence of a $20-\mu \mathrm{m}$-path length cuvette 


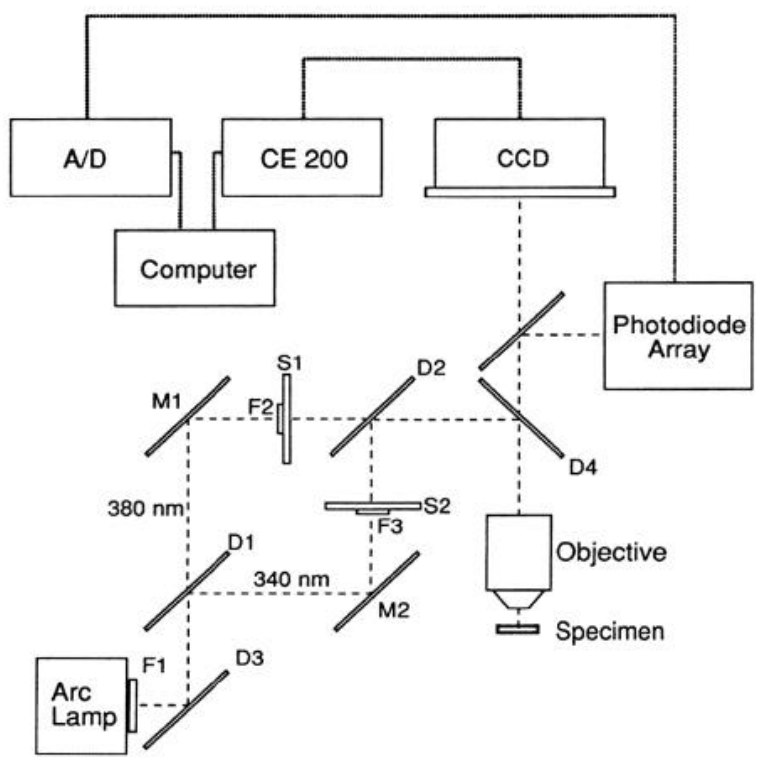

Figure 1. Schematic diagram of the imaging system. Infrared light from a mercury arc lamp was removed with an absorption filter (Fl, Melles Griot heat filter 03FHA043) and a custom dichroic mirror with a 360 $\mathrm{nm}$ transmission band (D3, "Fura cold mirror," Omega Optical, Brattleboro, VT). Dichroic mirrors $(D 1=D 2$; Omega Optical DC360LP) were used to split the remaining light into $340 \mathrm{~nm}$ and $380 \mathrm{~nm}$ components and to recombine them. Each component was separately gated (S1, S2) with a TTL controlled shutter (Vincent Assoc., Rochester, NY, $225 \mathrm{~L} 0 \mathrm{X} 0 \mathrm{Z} 5 \mathrm{HB}$ shutter assembly and $122-\mathrm{B}$ drive electronics). The mirrors $M 1$ and $M 2$ were UV coated front surface mirrors (Melles Griot $01 \mathrm{MFG} 027 / 028)$. The $380 \mathrm{~nm}$ band-pass filter $(F 2)$ was Omega Optical $380 \mathrm{DF} 10$, and the $340 \mathrm{~nm}$ band-pass filter $(F 3)$ was 340DF20. The dichroic mirror $D 4$ was Omega Optical DC410LP, and the barrier filter was Schott GG455. See text for further details.

filled with $140 \mu \mathrm{M}$ of unbound fura-2 (similar in intensity to the soma of a filled neuron) was compared to that of a $300-\mu$ m-thick slice. For stratum radiatum, the ratio of slice fluorescence to fura- 2 fluorescence was approximately 0.15 for $340 \mathrm{~nm}$ excitation and 0.09 for $380 \mathrm{~nm}$ excitation. Background fluorescence intensity was different for different regions of the slice, with the relative values of $1 / 0.85 / 1 / 0.95$ for stratum oriens/stratum pyramidale/stratum radiatum/stratum moleculare. Background fluorescence differences within a region were typically substantially smaller than those observed for different regions of the slice, and background fluorescence could be subtracted to better than $5 \%$ over the field of view. For finer dendritic branches, nonuniformities in background fluorescence could produce inaccuracies in the calculated $\mathrm{Ca}^{2+}$ concentrations. Therefore, only $\mathrm{Ca}^{2+}$ concentrations from cellular regions for which the fura- 2 fluorescence was $10 \times$ larger than corrected background fluorescence are reported or displayed.

Calibrations for the dependence of fura-2 fluorescence on $\mathrm{Ca}^{2+}$ were performed using $20-\mu \mathrm{m}$-thick precision path length microslides (Vitro Dynamics Inc., Rockaway, NJ, 5005). For CCD imaging, $\left[\mathrm{Ca}^{2+}\right]_{i}$ was calculated using the ratio method. $R_{\min }$ was determined using a solution consisting of $140 \mu \mathrm{m}$ fura-2, $130 \mathrm{~mm} \mathrm{KCl}, 10 \mathrm{~mm}$ K-HEPES, $2 \mathrm{~mm}$ EGTA, and $0 \mathrm{mM} \mathrm{Ca}^{2+}$ at $30-32^{\circ} \mathrm{C} . R_{\max }$ was determined using the same solution to which $5 \mathrm{~mm} \mathrm{Ca}^{2+}$ had been added. The $340 \mathrm{~nm} / 380 \mathrm{~nm}$ fluorescence ratio measured for unstimulated cells was typically lower than $R_{\min }$, indicating that values obtained by uncorrected in vitro calibrations of fura- 2 were not suitable. Such differences between in vitro values and values obtained within cells have been widely reported (Poenie et al., 1986).

Attempts at in situ calibrations for cells within the slice were unsuccessful. Such calibrations rely on equilibrating the cell interior with solutions of known $\mathrm{Ca}^{2+}$ concentrations and creating a calibration curve relating ratio to $\mathrm{Ca}^{2+}$. Thirty minute bath applications of the $\mathrm{Ca}^{2+}$ ionophores bromo-A23187 (5 $\mu \mathrm{M}$; Molecular Probes) and ionomycin ( $1 \mu \mathrm{M}$; Calbiochem) failed to raise the fura-2 fluorescence ratios. Since stimulus-evoked field potentials also remained stable, we interpret this inability of the ionophores to render the cells permeable to $\mathrm{Ca}^{2+}$ to be
A

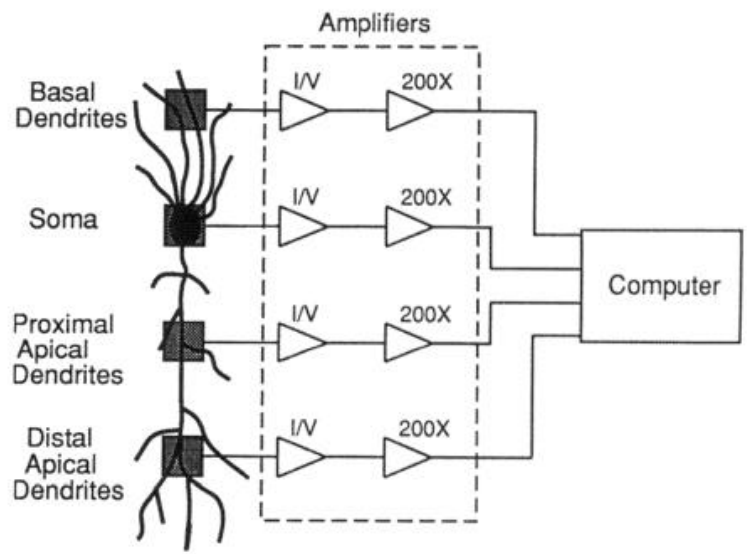

B

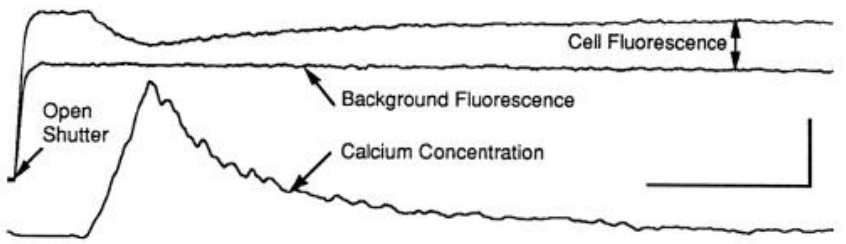

Figure 2. High-temporal-resolution $\mathrm{Ca}^{2+}$ measurements. $A$, Schematic diagram of the four-element photodiode array. B, Upper two traces are measurements of $380 \mathrm{~nm}$ excited fluorescence intensity made using one photodiode of the array, with the diode positioned over the background and then over the cell dendrite during a stimulus train. Using these two traces and standard ratio measurements of the prestimulus calcium concentration, the cell fluorescence changes were converted to the $\mathrm{Ca}^{2+}$ concentrations shown in the lower trace (see text). Calibration bar corresponds to $1 \mathrm{pA}$ for the fluorescence intensity traces and to $200 \mathrm{nM}$ $\left[\mathrm{Ca}^{2+}\right]_{i}$ for the lower trace of calcium concentration. Time calibration, $1 \mathrm{sec}$ (for both traces).

due to the failure of these hydrophobic molecules to penetrate significantly into the slice. Being unable to perform an in situ calibration, we used a viscosity correction factor of 0.7 , which is typical of that found in similar preparations. With this correction, our measured fura- 2 ratios of cells at rest correspond to $\left[\mathrm{Ca}^{2+}\right]$ of $50-70 \mathrm{nM}$.

To determine if differences in relative absorption or scatter for 340 $\mathrm{nm}$ and $380 \mathrm{~nm}$ excitation wavelengths could lead to a ratio shift with depth in the slice, a simple experiment was performed. Fluorescent beads were glued to the tip of a microelectrode, and two image pairs were taken of the fluorescence produced by these beads, one direct and one with a slice in the light path. The image through the slice was significantly blurred by scattering and was dim, but no ratio change could be detected to within the accuracy of our measurement $(5 \%)$, indicating that such effects do not contribute significantly to an error in ratio determination (especially since imaged cells were within $100 \mu \mathrm{m}$ of the surface).

Even for these relatively high-spatial-resolution images scatter makes it impossible to distinguish between spines and dendrites: each pixel records a fluorescence signal with contributions from both dendrites and spines, with the relative contributions determined by their relative volume. Higher-resolution imaging of dendrites passing within $10 \mu \mathrm{m}$ of the surface in unfixed tissue (Nikon $40 \times$ Fluor oil objective, 1.3 NA) showed fluorescent spines, demonstrating that spines did fill with fura-2 and contribute to our measurements.

High-speed low-spatial-resolution measurements of calcium transients. High-temporal-resolution measurements of $\mathrm{Ca}^{2+}$ transients were made using four photodiodes to record the fluorescence produced by $380 \mathrm{~nm}$ illumination (Fig. 2A; Regehr and Tank, 1990). The photodiodes were arranged in a line, and for the optics used in these studies each one collected light from a $45 \times 45 \mu \mathrm{m}$ area on the sample with $160 \mu \mathrm{m}$ separation. The photodiodes (Hamamatsu S1087-01) operated in photoconduction mode, and current-to-voltage conversion was accomplished by standard methods using a $1 \mathrm{G} \Omega$ feedback resistor. The 
signal was further amplified $200 \times$, filtered with a time constant of 25 msec, digitally sampled at $1 \mathrm{msec}$ intervals, and storcd on a Macintosh IIx computer. The data were subsequently digitally filtered using a Gaussian filter. The array was aligned by positioning the slice so that the apical dendrite-basal dendrite axis of the fluorescent neuron was parallel to the photodiode array, with one of the middle photodiodes centered to record from the soma. The other three photodiodes recorded transients in the basal dendrites, proximal-apical dendrites, and distalapical dendrites. Resting $\mathrm{Ca}^{2+}$ levels were determined using the ratio method (similar to that used for the CCD). Then, fluorescence intensity produced by $380 \mathrm{~nm}$ illumination was measured locked to the stimulus (Fig. $2 B$ ). This wavelength was chosen primarily because it was possible to obtain larger signal-to-noise ratios: the $380 \mathrm{~nm}$ illumination was typically brighter than $340 \mathrm{~nm}$ illumination. A rise in $\mathrm{Ca}^{2+}$ caused a decrease in $380 \mathrm{~nm}$ excited fluorescence intensity. Since resting $\mathrm{Ca}^{2+}$ levels before and after the train had becn determined by ratio measurement, and bleaching during a $5 \mathrm{sec}$ illumination of fura- 2 was less than $1 \%$, this fluorescence change could be converted to $\mathrm{Ca}^{2+}$ using the equations

$$
\begin{aligned}
F_{\text {max }} & =\left(1+\left[\mathrm{Ca}^{2+}\right]_{\mathrm{pre}}\right) /\left(\left[\mathrm{Ca}^{2+}\right]_{\mathrm{pre}}+S_{j 2} / S_{b 2}\right), \\
F_{\min } & =\left(S_{f 2} / S_{h 2}\right) F_{\max }, \\
{\left[\mathrm{Ca}^{2+}\right] } & =K_{d}\left(F-F_{\min }\right) /\left(F_{\max }-F\right),
\end{aligned}
$$

where $\left[\mathrm{Ca}^{2+}\right]_{\text {pre }}$ is the $\mathrm{Ca}^{2+}$ concentration computed using the ratio method (Eq. 5 from Grynkiewicz et al., 1985) just before the continuous illumination with $380 \mathrm{~nm}$ light. Using the notation of Grynkiewicz, $F_{\text {max }}$ is the fluorescence intensity produced by $380 \mathrm{~nm}$ illumination when all of the fura- 2 is bound to $\mathrm{Ca}^{2+}, F_{\min }$ is the fluorescence intensity produced by $380 \mathrm{~nm}$ illumination when none of the fura-2 is bound to $\mathrm{Ca}^{2+}$, $S_{f 2} / S_{b 2}$ is the ratio of fluorescence for bound versus free $\mathrm{Ca}^{2+}$ determined by in vitro calibrations, $F$ is the fluorescence produced by $380 \mathrm{~nm}$ illumination during the stimulus train, and $K_{d}$ is the fura- 2 dissociation constant. Figure $2 B$ shows an example of background fluorescence, changes in fura- 2 fluoresence for a dendritic region during synaptic activation, and the $\mathrm{Ca}^{\text {' }}$ concentration versus time computed using this single-wavelength method.

Furaptra imaging. Fura-2 has a $K_{d}$ of approximately $200 \mathrm{~nm}$ at the temperatures and ionic strengths used in these experiments and is thus most suited to measuring $\mathrm{Ca}^{2+}$ in the range of $20 \mathrm{nM}$ to $2 \mu \mathrm{M}$. To estimate higher concentrations, the fluorophore furaptra (Raju et al., 1989) was used for some experiments. Furaptra (also known as Magfura, Molecular Probes 1290 ) is a fluorescence-ratio indicator similar to fura-2, and the same $340 \mathrm{~nm} / 380 \mathrm{~nm}$ illumination and imaging system can be used. Furapta differs from fura-2 primarily in the dissociation constants for divalent cations, which are approximately $1.5 \mathrm{~mm}$ for $\mathrm{Mg}^{2+}$ and $50 \mu \mathrm{M}$ for $\mathrm{Ca}^{2+}$. At rest, essentially all bound fluorophore is associated with $\mathrm{Mg}^{2+}$, and $\left[\mathrm{Mg}^{2+}\right]_{\text {rest }}$ can be determined with relatively little interference from $\mathrm{Ca}^{2+}$ binding (assuming $\mathrm{Ca}^{2+}$ is about $50-70 \mathrm{~nm}$ based upon fura- 2 measurements). Large $\mathrm{Ca}^{2+}$ transients can, however, produce furaptra fluorescence changes such as have been measured in muscle (Konishi et al., 1991).

Experimental procedures were similar to those used for fura- 2 imaging except that cells were typically filled to greater than $500 \mu \mathrm{M}$ furaptra by iontophoresis for 10-15 min using microelectrodes containing $28 \mathrm{mM}$ furaptra, $100 \mathrm{~mm} \mathrm{KCl}$. It was possible to use such high fluorophore concentrations without greatly interfering with $\mathrm{Ca}^{2+}$ levels in the cell due to furaptra's much higher dissociation constant for $\mathrm{Ca}^{2+}$. It was also desirable to have higher fluorophore levels to improve signal-tonoise ratios since ratio changes were typically much smaller than those observed for fura-2.

Calibrations were performed in a manner similar to that used for fura2. Two types of CCD imaging experiments were conducted with furaptra. One approach was to do essentially the same ratio measurements for $20 \mathrm{~Hz}$ and $100 \mathrm{~Hz}$ stimulation as that used for fura-2 imaging (as in Fig. 3), but with the pseudocolor image formed from the ratio change (see, e.g., Fig. $7 H$ ). A second approach (similar to that employed in photodiode experiments) was to take a $340 \mathrm{~nm} / 380 \mathrm{~nm}$ image pair, and during the stimulus train take a series of images produced by $380 \mathrm{~nm}$ illumination. This approach allowed better temporal resolution and enhanced signal-to-noise ratio since the rather small $340 \mathrm{~nm}$ excitation signal was the limiting factor for the signal-to-noise ratio. For these experiments (see Fig. $7 B-F$ ), images are displayed as the negative per- centage change in fluorescence (increases in bound fluorophore decreases the intensity of fluorescence produced by $380 \mathrm{~nm}$ excitation).

\section{Results}

\section{A. General properties of calcium accumulations produced by} synaptic activation

Our experiments were designed to determine the spatial distribution and time course of calcium accumulations that occur in CAl hippocampal pyramidal cells in response to synaptic activation. We have focused on synaptic activation that can induce LTP. In most experiments, two different stimulus trains were employed: (1) a high-frequency short train $(100 \mathrm{~Hz}, 0.5-1 \mathrm{sec}$ duration) and (2) a moderate-frequency longer train $(20 \mathrm{~Hz}, 5$ sec). Results of earlier experiments (Regehr et al., 1989; Regehr and Tank, 1990a) suggested that the high-frequency shorter train accentuates calcium accumulations induced by ionic currents through NMDA receptor-coupled ion channels while the longer train at lower frequency produces large widespread accumulations that are insensitive to the NMDA receptor antagonist AP5. This distinction is explored in much greater detail in the present experiments; the difference in accentuation between the two stimulus trains is shown to be a robust phenomenon.

In the following, we first describe the general features of calcium accumulations produced by these two stimulus trains. For simplicity, we separate the description of these features into the spatial distribution of accumulations measured with high-spatial-resolution CCD imaging methods and then subsequently describe the features of the time course of accumulations measured with a higher-time-resolution photodiode array. For many of the experiments, calcium accumulations are separated into two components based upon sensitivity to the NMDA receptor antagonist AP5. Note that the AP5-sensitive and -insensitive components are not equivalent to a component produced by $\mathrm{Ca}^{2+}$ influx through NMDA receptor channels and one produced by $\mathrm{Ca}^{2+}$ influx through voltage-dependent $\mathrm{Ca}^{2+}$ channels (VDCCs), respectively (see Discussion). Following the general description of the accumulations (section A), we will separately present the results of experiments that attempt to characterize these two components further: the AP5-sensitive component (section B) and the AP5-insensitive component (section C). A summary of the results of afferent fiber stimulation experiments is provided by Table 1 .

High-spatial-resolution imaging. Imaging of fura- 2 filled single neurons in brain slice (Tank et al., 1988) with high-resolution CCD cameras can provide micrometer-scale information on the spatial pattern of calcium levels. At high spatial resolution, temporal resolution is limited by signal-to-noise considerations, and for the conditions used in these experiments, CCD image pairs suitable for calcium maps are limited to less than $2 / \mathrm{sec}$. The general features of the spatial distribution of calcium accumulations produced in C.A 1 hippocampal pyramidal cells by afferent fiber stimulation of the Schaffer collateral system are shown in Figure 3. An enlarged fluorescence image ( $380 \mathrm{~nm}$ excitation) of the cell is shown in Figure $3 G$, with the basal dendrites to the right and the apical dendrites to the left. A threshold mask, determined from the intensity of $380 \mathrm{~nm}$-induced fluorescence, was used to define the pixels that are displayed in the pseudocolor images of calcium levels. Image pairs were taken each second to form a series of pseudocolor maps that approximate the average calcium concentration for a $1 \mathrm{sec}$ period (see Materials and Methods). 
Table 1. Summary of experiments measuring synaptically evoked calcium accumulations produced by stimulation of stratum radiatum for 100 pulses delivered at $100 \mathrm{~Hz}$ or $20 \mathrm{~Hz}$

\begin{tabular}{|c|c|c|c|c|c|c|c|c|c|c|}
\hline & \multirow[b]{2}{*}{$\begin{array}{l}\text { Stimulus } \\
\text { frequency } \\
(\mathrm{Hz})\end{array}$} & \multirow[b]{2}{*}{$\begin{array}{l}\text { Special } \\
\text { conditions }\end{array}$} & \multirow[b]{2}{*}{$\begin{array}{l}\text { Method } \\
\text { of } \\
\text { recording }\end{array}$} & \multirow[b]{2}{*}{$\begin{array}{l}\text { Trial } \\
\text { conditions }\end{array}$} & \multicolumn{4}{|c|}{ Peak calcium accumulations } & \multirow[b]{2}{*}{$n$} & \multirow{2}{*}{$\begin{array}{l}\text { Localizated } \\
\text { AP5- } \\
\text { sensitive } \\
\text { component }\end{array}$} \\
\hline & & & & & $\begin{array}{l}\text { Basal } \\
\text { dendrites }\end{array}$ & Soma & $\begin{array}{l}\text { Proximal- } \\
\text { apical } \\
\text { dendrites }\end{array}$ & $\begin{array}{l}\text { Distal- } \\
\text { apical } \\
\text { dendrites }\end{array}$ & & \\
\hline la & 100 & & $\mathrm{PD}$ & Control & 481 & 137 & 745 & 727 & 15 & \\
\hline $\mathrm{b}$ & & & $\mathrm{PD}$ & AP5 & 340 & 113 & 216 & 131 & 15 & \\
\hline $\mathrm{c}$ & & & PD & Control-AP5 & 141 & 24 & 529 & 596 & 15 & 15 of 15 \\
\hline $2 \mathrm{a}$ & 100 & & $\mathrm{CCD}$ & Control & 309 & 76 & 265 & 535 & 21 & \\
\hline $\mathrm{b}$ & & & $\mathrm{CCD}$ & AP5 & 303 & 73 & 250 & 176 & 21 & \\
\hline $\mathbf{c}$ & & & $\mathrm{CCD}$ & Control-AP5 & 6 & 3 & 15 & 359 & 21 & 20 of 21 \\
\hline $3 a$ & 20 & & PD & Control & 535 & 393 & 493 & 294 & 6 & \\
\hline $\mathbf{b}$ & & & PD & AP5 & 468 & 348 & 240 & 86 & 6 & \\
\hline $\mathrm{c}$ & & & PD & Control-AP5 & 67 & 45 & 253 & 208 & 6 & 3 of 6 \\
\hline $4 a$ & 20 & & $\mathrm{CCD}$ & Control & 460 & 163 & 439 & 133 & 10 & \\
\hline $\mathbf{b}$ & & & $\mathrm{CCD}$ & AP5 & 471 & 174 & 485 & 130 & 10 & \\
\hline $\mathrm{c}$ & & & $\mathrm{CCD}$ & Control-AP5 & -11 & -11 & -46 & 3 & 10 & 2 of 10 \\
\hline $5 a$ & 100 & High fura-2 & PD & Control & 132 & 86 & 87 & 100 & 5 & \\
\hline $\mathbf{b}$ & & High fura-2 & PD & AP5 & 168 & 102 & 81.7 & 40 & 3 & \\
\hline $\mathrm{c}$ & & High fura-2 & PD & Control-AP5 & -77 & -8.3 & 26.7 & 80 & 3 & 2 of 3 \\
\hline $6 a$ & 20 & High fura-2 & PD & Control & 293 & 108 & 215 & 170 & 3 & \\
\hline $\mathbf{b}$ & & High fura-2 & PD & AP5 & 353 & 118 & 320 & 170 & 2 & \\
\hline $\mathrm{c}$ & & High fura-2 & PD & Control-AP5 & -30 & -42 & -67 & 0 & 2 & 0 of 3 \\
\hline $7 \mathbf{a}$ & 100 & QX-314 & $\mathrm{CCD}$ & Control & 146 & 52 & 278 & 523 & 3 & \\
\hline $\mathbf{b}$ & & QX-314 & $\mathrm{CCD}$ & AP5 & 140 & 61 & 166 & 205 & 3 & \\
\hline $\mathrm{c}$ & & QX-314 & $\mathrm{CCD}$ & Control-AP5 & 5 & -9 & 52 & 351 & 3 & 3 of 3 \\
\hline $8 a$ & 20 & QX-314 & CCD & Control & 149 & 83 & 158 & 237 & 4 & \\
\hline b & & QX-314 & CCD & AP5 & 126 & 88 & 154 & 113 & 4 & \\
\hline $\mathrm{c}$ & & QX-314 & $\mathrm{CCD}$ & Control-AP5 & 23 & -5 & 4 & 124 & 4 & 2 of 4 \\
\hline $9 \mathrm{a}$ & 100 & PTX & $\mathrm{CCD}$ & Control & 353 & 93 & 455 & 545 & 2 & \\
\hline b & & PTX & $\mathrm{CCD}$ & AP5 & 260 & 80 & 273 & 255 & 2 & \\
\hline c & & PTX & $\mathrm{CCD}$ & Control-AP5 & 93 & 13 & 182 & 290 & 2 & 2 of 2 \\
\hline $10 \mathrm{a}$ & 20 & PTX & $\mathrm{CCD}$ & Control & 585 & 255 & 650 & 108 & 2 & \\
\hline $\mathrm{b}$ & & PTX & $\mathrm{CCD}$ & AP5 & 585 & 255 & 575 & 70 & 2 & \\
\hline $\mathrm{c}$ & & PTX & $\mathrm{CCD}$ & Control-AP5 & 0 & 0 & 75 & 38 & 2 & 1 of 2 \\
\hline
\end{tabular}

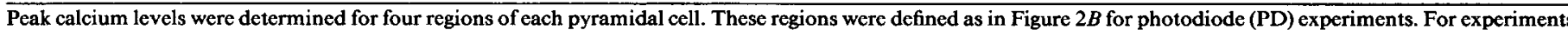

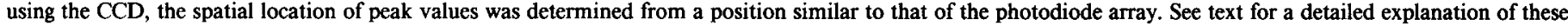
results.

Stimulation $(100 \mathrm{~Hz})$ in control saline (Fig. $3 \mathrm{~A}$; Table 1 , line 2a) produced widespread dendritic $\mathrm{Ca}^{2+}$ transients during the stimulus train (Fig. $3 A b$ ). Accumulations were small in the most distal-apical dendrites (to the left beyond the synaptically activated region), and in the soma (the blue region slightly to the right of center). Following termination of the stimulus, calcium levels returned rapidly to prestimulus levels, as shown in Figure $3 A c$. In the presence of AP5, large calcium transients were reduced in the region receiving synaptic input (Fig. $3 B$; Table 1 , line $2 b$ ) for 20 of 21 cells while accumulations in the proximal dendrites were largely unaltered. In Figure $3 C$, pixel-by-pixel subtraction of each image in Figure $3 B$ from the corresponding image in Figure $3 A$ reveals an AP5-sensitive component in the region receiving synaptic input (Fig. $3 \mathrm{Cb}$; Table 1 , line $2 c$ ).

In control saline, $20 \mathrm{~Hz}$ stimulation produced large $\left[\mathrm{Ca}^{2+}\right]_{i}$ increases in the proximal-apical and basal dendrites (Fig. $3 D$; Table 1, line 4a). Accumulations in synaptically activated regions (in this case, distal-apical dendrites) were much smaller than those observed during $100 \mathrm{~Hz}$ stimulation. The decay of $\left[\mathrm{Ca}^{2+}\right]_{i}$ to resting levels in cellular regions with different surface-tovolume ratios was nonuniform. This was particularly evident in the frame immediately following the termination of $20 \mathrm{~Hz}$ stimulation (Fig. $3 D g$ ). In thick dendritcs near the soma, $\mathrm{Ca}^{2+}$ remained elevated longer than in finer branches. AP5 did not greatly alter the calcium accumulations observed for $20 \mathrm{~Hz}$ stimulation, as can be seen by comparing the accumulations in Figure $3 D$ with the accumulations in Figure $3 E$ (Table 1, lines $4 b, c)$. A pixel-by-pixel subtraction of accumulations in the presence of AP5 from those in control saline did, however, reveal a small AP5-sensitive component in the distal-dendritic region (to the left of Fig. $3 F, c, d$, there is a very subtle effect). In general, for $20 \mathrm{~Hz}$ stimulation this localized AP5-sensitive accumulation was small and not reliably observed (seen in 2 of 10 experiments). In six cells tested that showed small or no AP5-sensitive component at $20 \mathrm{~Hz}$, a large component was observed at 100 $\mathrm{Hz}$.

The images in Figure 3 and the summary of our experiments in Table 1 demonstrate that rather than being restricted to synaptically activated dendritic regions, calcium accumulations were widespread. The accumulations in non-synaptically-activated regions were not greatly reduced by AP5. As predicted by the calcium induction hypothesis, an AP5-blockable component of 

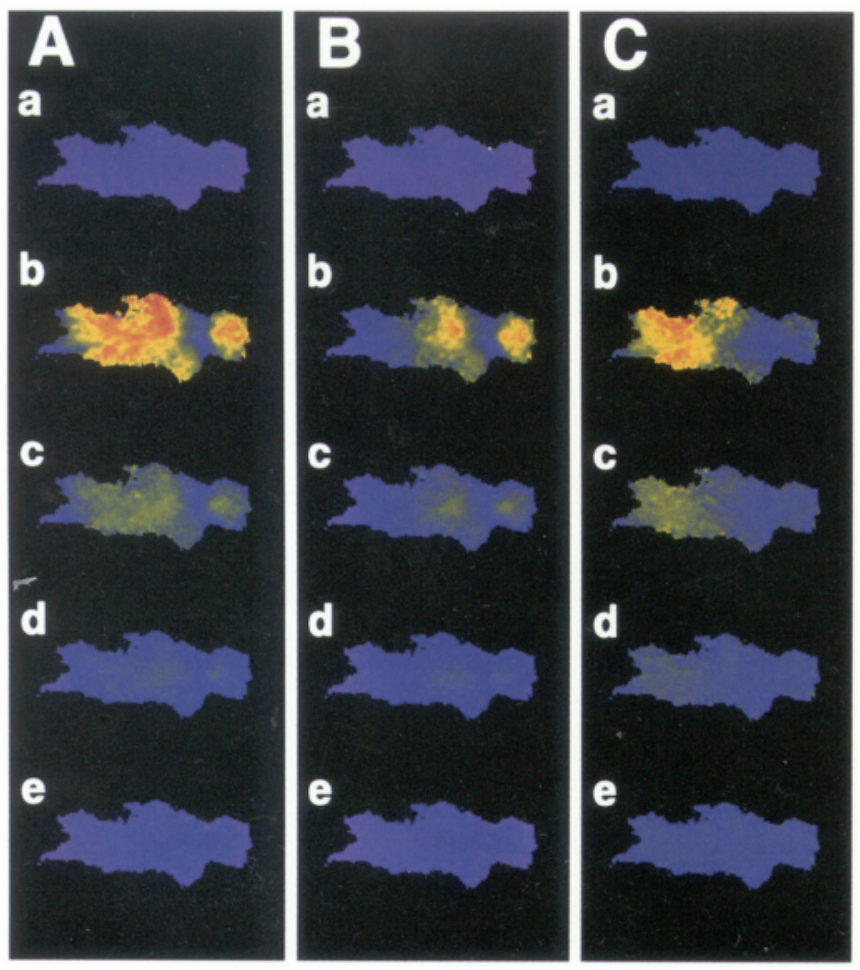

$\mathrm{nM}$

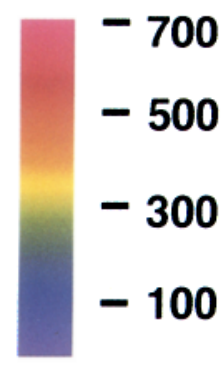

$\left[\mathrm{Ca}^{2+}\right]_{i}$
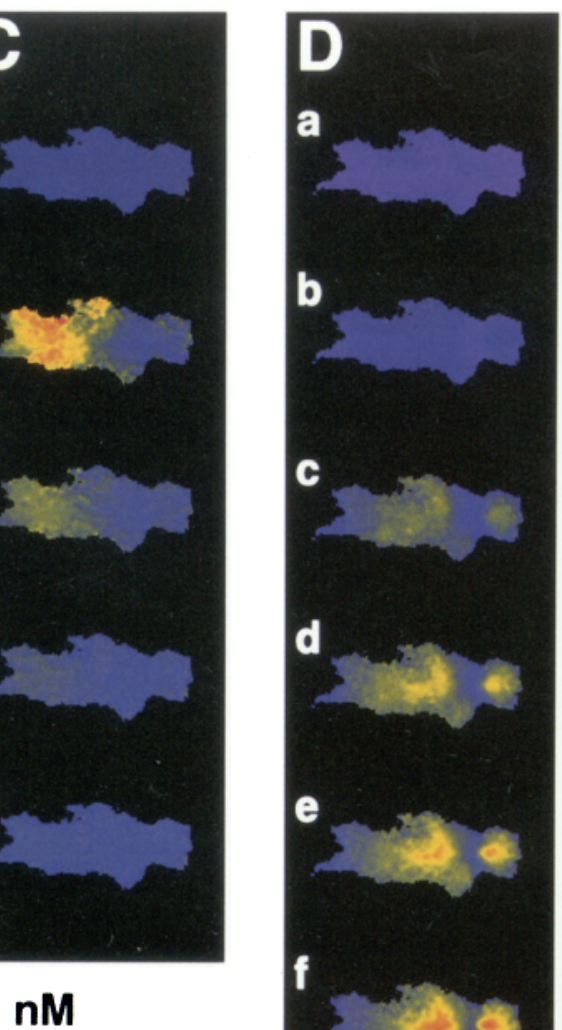

b

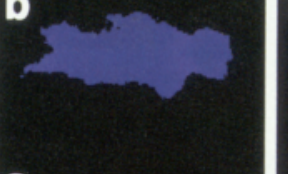

6

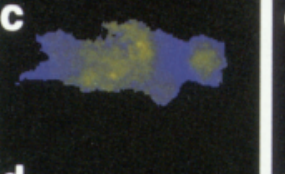

d
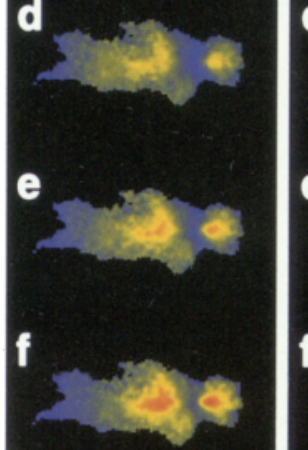

450

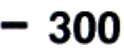

$-150$

$-0$

$--150$
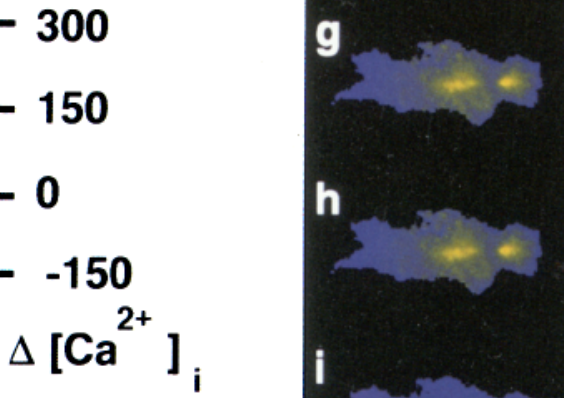

i

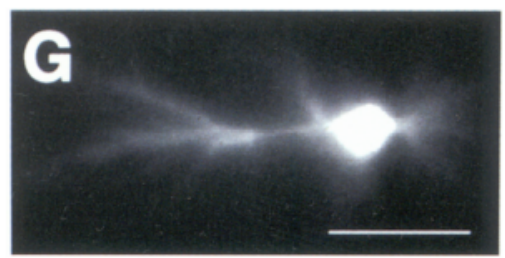

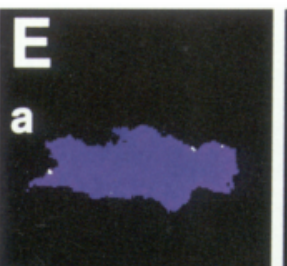
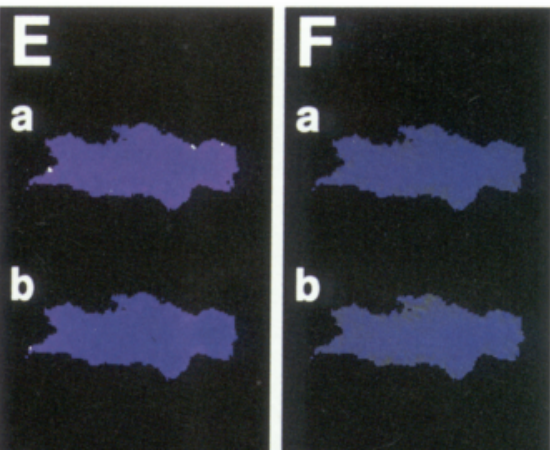

b

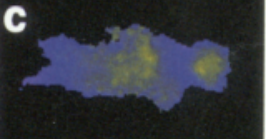

c
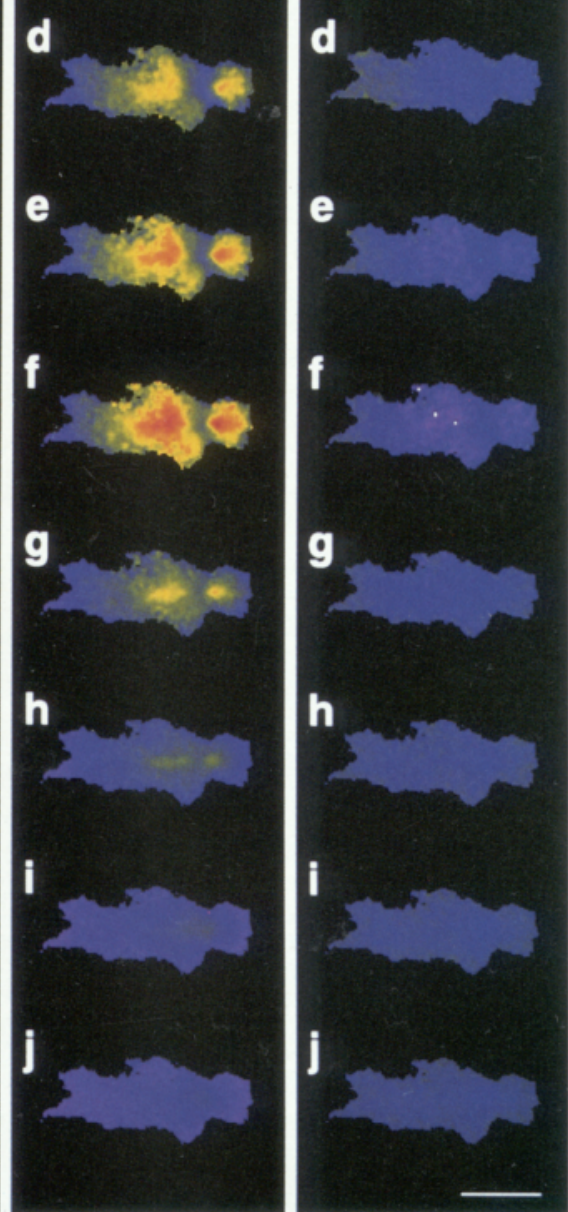

Figure 3. Spatially resolved $\mathrm{Ca}^{2+}$ accumulations measured in control and AP5-containing saline. For the cell whose fluorescence image is shown in $G$, spatial maps of $\mathrm{Ca}^{2+}$ concentration were formed from the ratios of $340 \mathrm{~nm}$ and $380 \mathrm{~nm}$ images. $A$, Stimulation at $100 \mathrm{~Hz}$ in control saline; $B, 100 \mathrm{~Hz}$ stimulation in AP5-containing saline; $C$, AP5-sensitive accumulations formed by subtracting $\mathrm{Ca}^{2+}$ accumulations observed in AP5containing saline from those observed in control saline (i.e., $A$ and $B$ ); $D, 20 \mathrm{~Hz}$ stimulation in control saline; $E, 20 \mathrm{~Hz}$ stimulation in AP5containing saline; $F$, AP5-sensitive accumulations formed by subtracting $\mathrm{Ca}^{2+}$ accumulations observed in AP5-containing saline from those observed in control saline (i.e., $D$ and $E$ ). A series of image pairs were acquired every second. Image acquisition was synchronized to stimulation that began immediately following image (a). For $A-C$, there is an additional delay of $3 \mathrm{sec}$ between $d$ and $e$. For $D-F$, there is an additional delay between images $h$ and $i$ of $3 \mathrm{sec}$ and between images $i$ and $j$ of $5 \mathrm{sec}$. Color scale to the left applies to absolute measurements of $\left[\mathrm{Ca}^{2+}\right]_{i}$ in $A, B, D$, and $E$; color scale to the right applies to the maps of $\Delta\left[\mathrm{Ca}^{2+}\right]_{i}$ in $C$ and $F$. Scale bars: $F$ (for $A-F$ ) and $G, 200 \mu \mathrm{m}$.

calcium accumulation was observed in synaptically activated regions. Consistent with the frequency dependence of LTP induction and with computer modeling studies, this component was much higher for $100 \mathrm{~Hz}$ than for $20 \mathrm{~Hz}$ stimulation.

High-temporal-resolution measurements. We used a four-el- ement parallel-readout photodiode array to make high temporal $\left[\mathrm{Ca}^{2+}\right]_{i}$ measurements. Accumulations are shown for two cells to demonstrate the consistent features and to call attention to aspects of the transients that were variable. The stimulus electrode was positioned to activate maximally fibers synapsing on 

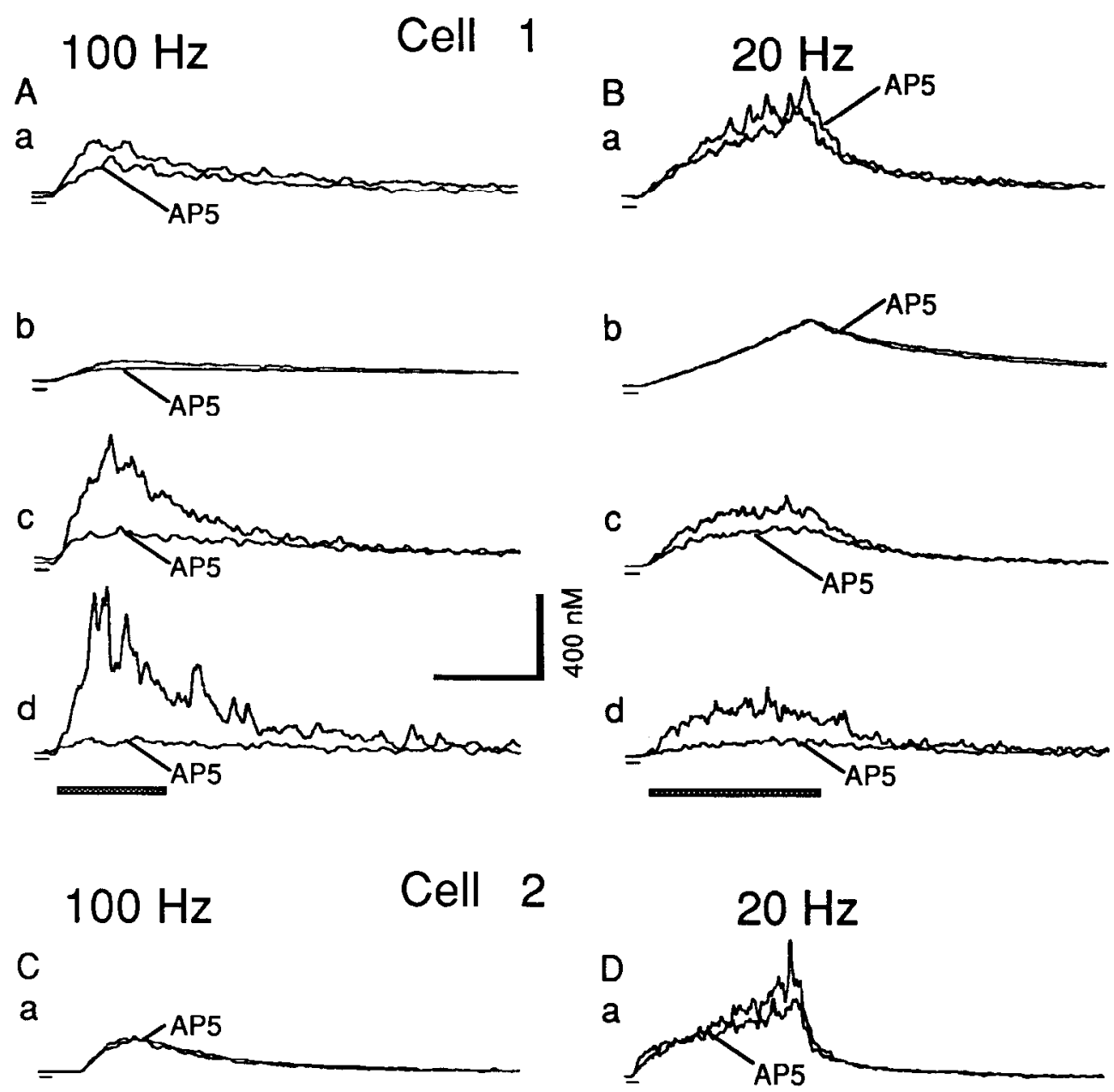

Figure 4. High-temporal-resolution measurements of $\mathrm{Ca}^{2+}$ accumulations for stimulus trains delivered to distalapical dendrites in control and AP5containing saline: basal dendrites $(a)$, soma (b), proximal-apical dendrites $(c)$ and distal-apical dendrites $(d)$. Calcium transients are shown for Cell 1 in response to $100 \mathrm{~Hz}$ stimulation $(A)$ and $20 \mathrm{~Hz}$ stimulation $(B)$, and for Cell 2 in response to $100 \mathrm{~Hz}(C)$ and $20 \mathrm{~Hz}$ stimulation $(D)$. Stimulation periods are indicated by the bar positioned beneath each set of figures. Time calibration: $A$ and $C, 1 \mathrm{sec} ; B$ and $D, 3.3 \mathrm{sec}$.

b
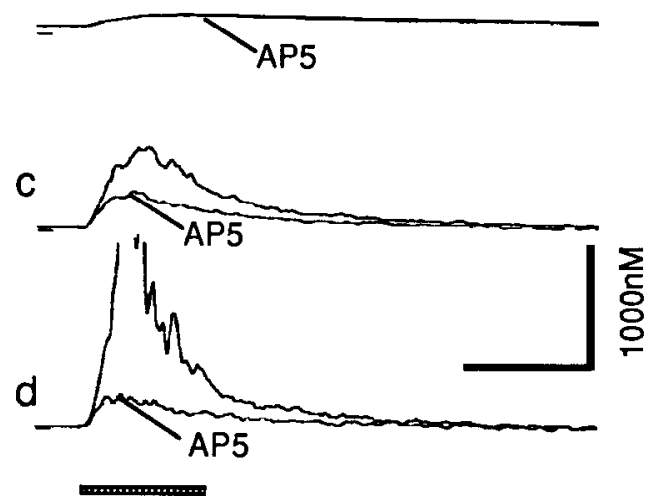

b

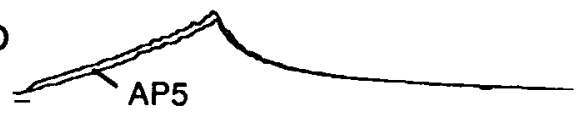

distal-apical dendrites. Large AP5-sensitive $\mathrm{Ca}^{2+}$ accumulations, primarily localized to regions receiving synaptic input, were reliably produced by $100 \mathrm{~Hz}$ stimulation (Fig. $4 A d, C d$ ). Much smaller AP5-sensitive accumulations were occasionally observed in the basal dendrites (Fig. 4Aa), but they were not consistently seen (Fig. 4Ca). The AP5-sensitive component for $20 \mathrm{~Hz}$ stimulation was usually very small, and in some cases none was detected. In cases where it was observed, either it was seen in distal-apical dendrites for the duration of the stimulus as shown in Figure $4 B d$, or it was not well localized to the distal-apical dendrites, as in Figure $4 C d$, or it did not persist for the duration of the stimulus, as in Figure $4 D c$.

AP5 reversibly decreased the amplitude of the calcium transients in synaptically activated regions. This is demonstrated in Figure 5. A cell was prepotentiated, and then three $100 \mathrm{~Hz}$ stimulus trains separated by $30 \mathrm{~min}$ were used to stimulate afferents in stratum radiatum. The first and third trains were in control saline, and the second train was in AP5-containing saline. Accumulations measured after returning to control saline were virtually identical to the initial accumulations in control 
A

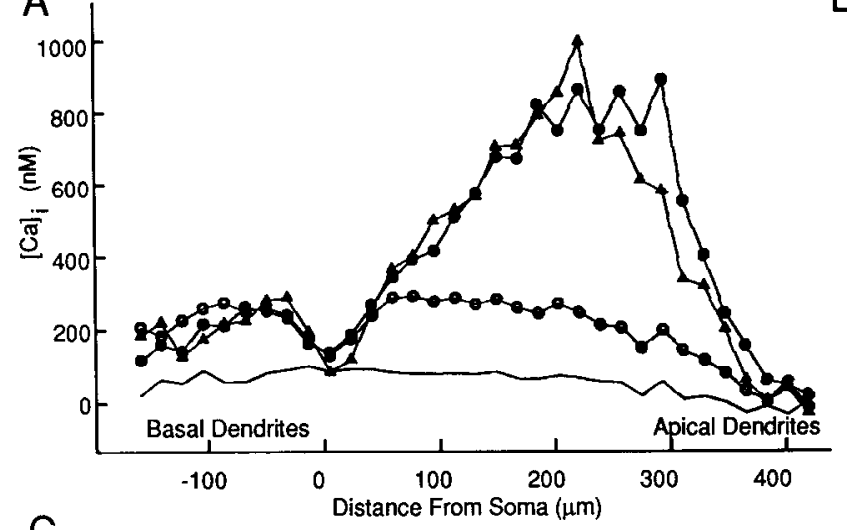

B

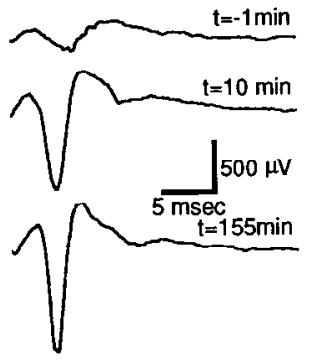

$\mathrm{C}$

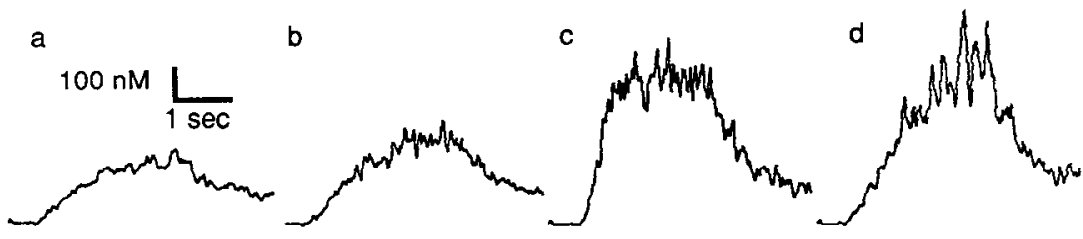

Figure 5. The effect of AP5 upon calcium accumulations is reversible, and the effect of LTP induction on calcium accumulations produced by submaximal stimulation is consistent with the presynaptic inputs to the imaged neuron being potentiated. $A, \mathrm{Ca}^{2+}$ accumulation versus distance from the soma for $100 \mathrm{~Hz}$ stimulation in control saline (solid circles; $t=15 \mathrm{~min}$ ), AP5-containing saline (open circles; $t=45 \mathrm{~min}$ ), and control saline (solid triangles; $t=75 \mathrm{~min}$ ). Resting calcium level was not appreciably changed by stimulation and is indicated by a solid line. $B$, Population spikes measured near the soma show that following stimulation at $t=0$ min there was a persistent increase in the population spike amplitude (note: upper trace is from $1 \mathrm{~min}$ before stimulation). $C$. Effect of the induction of LTP on the calcium accumulations in basal dendrites versus time occurring in response to submaximal $(20 \mathrm{~Hz}, 5 \mathrm{sec})$ stimulation in AP5-containing saline, $t=0(a)$; control saline, $t=30 \mathrm{~min}(b)$; control saline, $t=60 \mathrm{~min}(c)$; and AP5-containing saline, $t=90 \mathrm{~min}(d)$. Following LTP induction, there was an increase in calcium accumulation produced by submaximal stimulation.

saline. Figure 5 also shows an example of the population spike enhancement produced by tetanic stimulation. For all cases reported, high-frequency stimulation in control saline produced potentiation as judged by a $50 \%$ increase in either the population spike amplitude or the field postsynaptic potential slope that persisted for $10 \mathrm{~min}$ following tetanic stimulation.

High levels of fura-2 affect calcium accumulations. To obtain good signal-to-noise $\mathrm{Ca}^{2+}$ measurements in the presence of high background fluorescence levels, it is desirable to have as much fluorophore present as possible; but at what levels does fura-2 significantly perturb $\mathrm{Ca}^{2+}$ dynamics? High concentrations of a fast $\mathrm{Ca}^{2+}$ buffer with a low dissociation constant such as fura-2 could compete with intrinsic $\mathrm{Ca}^{2+}$ binding proteins and alter both the time dependence and amplitude of $\mathrm{Ca}^{2+}$ accumulations (Sala and Hernandez-Cruz, 1990; D. W. Tank, K. R. Delaney, and W. G. Regehr, unpublished observations). We therefore attempted to determine if LTP was occurring in the pyramidal cells that were imaged with the low fura- 2 concentrations that were typical of the majority of our experiments, and also to test directly if high fura-2 levels affect the amplitude and decay kinetics of calcium transients.

Elevation of calcium buffers in the postsynaptic cell blocks LTP induction (Lynch et al., 1983; Malenka et al., 1988). Did tetanic stimulation enhance synaptic inputs to cells filled with fura-2? We addressed this question by measuring calcium transients produced by submaximal-intensity test trains before and after the induction of LTP. This is shown in Figure $5 \mathrm{C} . \mathrm{Ca}^{2+}$ accumulations in the basal dendrites are plotted for low-intensity test trains delivered in AP5 (Fig. $5 \mathrm{Ca}$ ), control (Fig. $5 \mathrm{Cb}$, control (Fig. $5 C$ c), and AP5 saline (Fig. $5 C d$ ). Note that the initial stimulus, performed in AP5, did not enhance subsequent accumulations, but that the second tetanus, performed in control saline, did. The increase was only produced by tetanic stimulation in normal saline, not in AP5-containing saline. This kind of AP5-sensitive potentiation of calcium accumulation was typical of submaximal stimulus intensities $(n=4)$. For stimulus intensities that produced near-maximal population spike amplitude, this enhancement was not observed.

To investigate further the possibility that fura- 2 modifies the observed $\mathrm{Ca}^{2+}$ accumulations, cells were filled with different concentrations of fura-2. Transients in cells filled with either 50 $\mu \mathrm{M}$ or $100 \mu \mathrm{M}$ fura- 2 were qualitatively similar. The presence of 250-600 $\mu \mathrm{M}$ fura-2 reduced $\mathrm{Ca}^{3+}$ accumulations and slowed the return of calcium to resting levels (Fig. 6; Table 1, lines 5, 6). AP5-insensitive accumulations in the proximal dendrites were about half as large as accumulations for 50-150 $\mu \mathrm{M}$ fura2 , and AP5-sensitive accumulations in the dendritic regions near stimulated afferents were reduced more than sevenfold. For fura- 2 in the range of 50-150 $\mu \mathrm{M}$ following high-frequency stimulation, dendritic calcium decays were better fit with a double exponential decay with typical time constants of $250-500 \mathrm{msec}$ for the fast component and 2-4 sec for the slow component (Fig. $6 D$ ). When fura- 2 concentrations were $300-600 \mu \mathrm{M}$, the return of calcium to resting levels was well fit by a single exponential with a time constant of 4-8 sec (Fig. $6 \mathrm{C}$ ). Thus, 250-600 $\mu \mathrm{M}$ fura-2 appreciably adds to the buffer capacities of the intrinsic buffers and both reduces the amplitude and slows the decay.

Fluorescence changes in furaptra-filled pyramidal cells produced by synaptic stimulation. Experiments were also conducted using the fluorescent divalent ion indicator furaptra $(n=6$ cells; Raju et al., 1989). With its low affinity for $\mathrm{Ca}^{2+}$, this probe is well suited for measuring large calcium transients that would 
A a

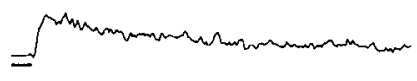

b
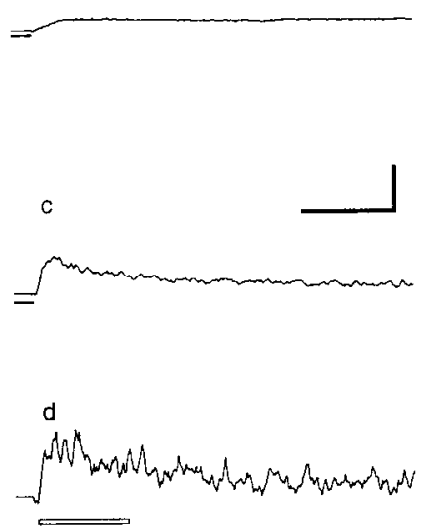

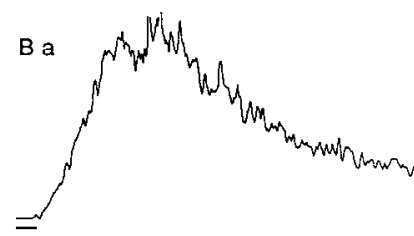

b
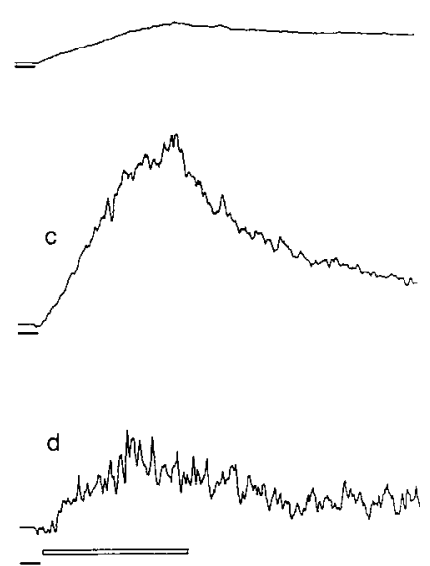
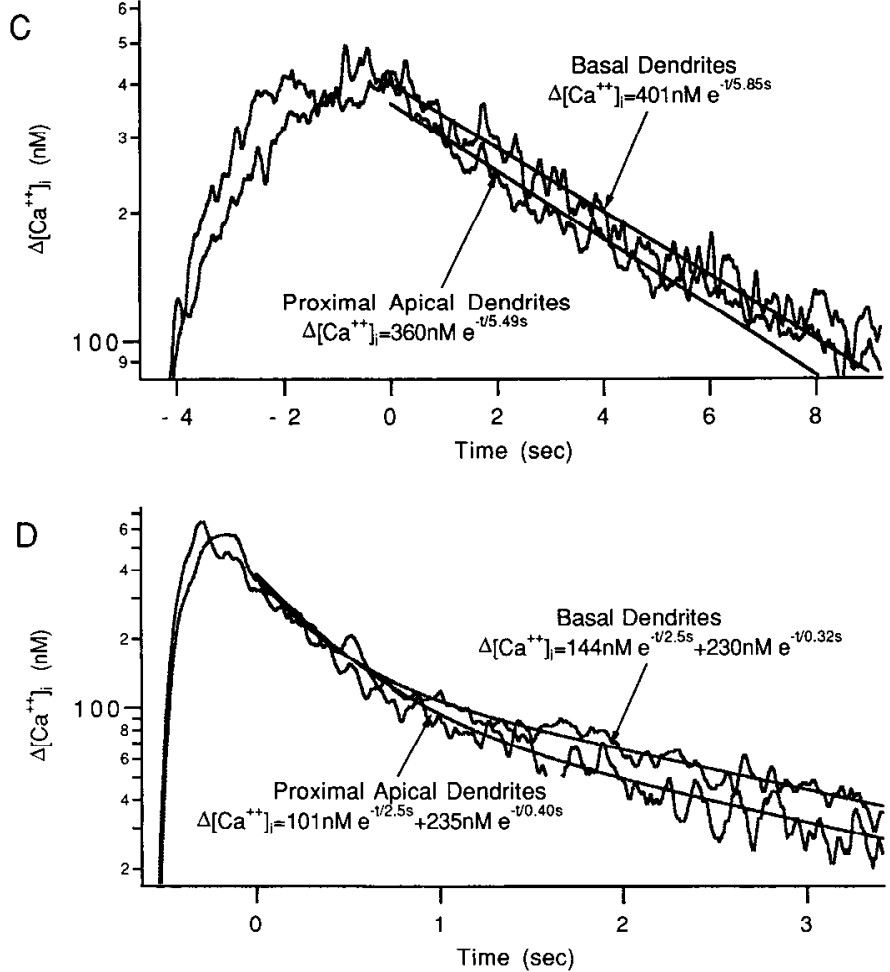

Figure 6. High levels of fura-2 affect $\mathrm{Ca}^{2+}$ accumulations. The experiment is similar to Figure 4 except that the cell was filled with an estimated $300 \mu \mathrm{M}$ fura- 2 for the data in $A-C$. $a$, basal dendrites; $b$, soma; $c$, proximal-apical dendrites; and $d$, distal-apical dendrites. Calcium transients are shown in response to $100 \mathrm{~Hz}$ stimulation $(A)$ and $20 \mathrm{~Hz}$ stimulation $(B)$ in control saline. In $A d$ and $B d$, the duration of the stimulus train is represented by a bar. $C$, The time course of the return of calcium transients to resting levels is influenced by high concentrations of fura- 2 . The semi-logarithmic plot of $\left[\mathrm{Ca}^{2+}\right]_{i}$ following cessation of $20 \mathrm{~Hz}$ stimulation for the basal dendrites and apical dendrites. These decays are well fit by single exponentials. $D$, For a cell filled to an estimated $100 \mu \mathrm{M}$ fura-2, the return of calcium to resting levels is faster and follows a similar time course in basal, proximal dendritic regions with similar surface to volume ratios. These curves are better described with double exponential decays as shown. Time calibration: $A, 1 \mathrm{sec} ; B, 3.3 \mathrm{sec}$. Concentration calibration, $100 \mathrm{nM}\left[\mathrm{Ca}^{2+}\right]_{i}$.

saturate fura-2 (see Materials and Methods). As shown in Figure $7, A$ and $G$, pyramidal cells filled with furaptra were similar in appearance to cells filled with fura-2. Synaptic activation produced fluorescence changes as shown in Figure $7 B-F$. Fractional changes in fluorescence $(-\Delta F / F$, change in fluorescence produced by $380 \mathrm{~nm}$ excitation divided by fluorescence for the cell at rest) are shown in pseudocolor. Large fractional changes on this scale correspond to large changes in the concentration of divalents. Stimulation at $100 \mathrm{~Hz}$ produced large AP5-sensitive fluorescence changes in synaptically activated regions (Fig. $7 \mathrm{C}$, $D$ ). For $20 \mathrm{~Hz}$ synaptic activation in both AP5-containing saline (Fig. $7 E$ ) and control saline (Fig. 7F), small fluorescence changes were observed in proximal dendrites, but no accumulation in the region of synaptic activation was reliably observed. In a similar experiment (Fig. $7 G, H$ ), the AP5-sensitive change in fluorescence intensity ratio was spatially determined for a different cell. There is a large well-localized increase in the concentration of divalents in the region near the activated afferent fibers.

Some ambiguity exists for these ratio measurements since furaptra is sensitive to both $\mathrm{Ca}^{2+}$ and $\mathrm{Mg}^{2+}$ and ratio changes could be due to transients of either ion or a combination of the two. The AP5-sensitive ratio change for $100 \mathrm{~Hz}$ stimulation shown in Figure $7 H$ corresponded either to $\Delta\left[\mathrm{Ca}^{2+}\right]_{i}=4-10 \mu \mathrm{M}$, if all of the ratio change were due to $\mathrm{Ca}^{2+}$ binding, or to $\Delta\left[\mathrm{Mg}^{2+}\right]_{i}$ $=200-500 \mu \mathrm{M}$, if all of the ratio change were due to $\mathrm{Mg}^{2+}$ binding. A similar analysis suggested that AP5-insensitive $\mathrm{Ca}^{2+}$ accumulations were less than $2 \mu \mathrm{M}$ and AP5-sensitive accumulations produced by $20 \mathrm{~Hz}$ stimulation were less than $1 \mu \mathrm{M}$. If the fluorescence changes observed in these furaptra experiments are entirely due to increases in $\left[\mathrm{Ca}^{2}{ }^{1}\right]_{i}$, our results suggest that during $100 \mathrm{~Hz}$ stimulation in control saline, calcium levels near the activated synaptic regions are in the $4-10 \mu \mathrm{M}$ range where fura- 2 is saturated. Thus, fura- 2 measurements tend to underestimate $\left[\mathrm{Ca}^{2+}\right]_{i}$ under these conditions.

\section{B. Further characterization of the AP5-sensitive calcium accumulations}

We performed experiments to reveal further the properties of the AP5-sensitive component of $\mathrm{Ca}^{2+}$ accumulation that is in-

Figure 7. Experiments using the fluorophore furaptra suggest that $\mathrm{Ca}^{2+}$ levels in synaptically activated regions may be underestimated by fura-2 due to its relatively high $\mathrm{Ca}^{2+}$ affinity. Experiments were conducted similar to those described in Figure 3 except that cells were filled with high concentrations of furaptra rather than fura-2. $A$, An image of a furaptra-loaded cell produced by $380 \mathrm{~nm}$ excitation. A series of pseudocolor images was computed from a series of images produced by $380 \mathrm{~nm}$ excitation by pixel-by-pixel determination of $-\Delta F / F$ for each of these images relative to an image taken before commencing stimulation, and then $3 \times 3$ spatially filtering this image. Decreases in $380 \mathrm{~nm}$ excited fluorescence (i.e. larger values of $-\Delta F / F)$ corresponded to increases in intracellular divalent cation concentration as described in Materials and Methods. $B$, 

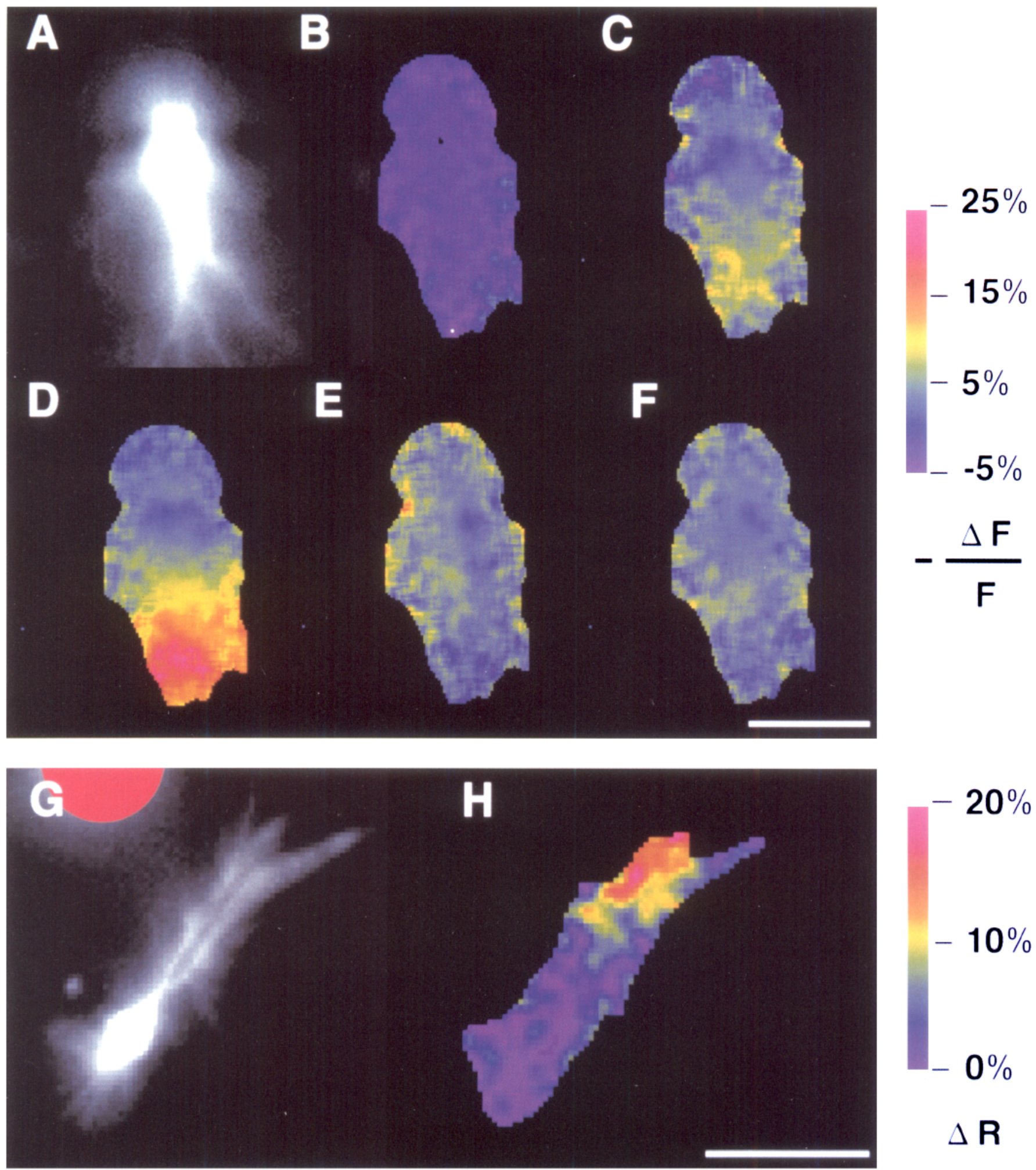

Pseudocolor image formed from two successive images before commencing stimulation. Only very small fluctuations in fluorescence intensities were observed in the absence of stimulation. Stimulation with a $100 \mathrm{~Hz}$ stimulus train produced fluorescence changes that correspond to large changes in divalent ion concentration in AP5-containing saline $(C)$ and control saline $(D)$. Images shown in $C$ and $D$ represent average fluorescence changes for $0.7-0.9 \mathrm{sec}$ after stimulation began. Stimulating at $20 \mathrm{~Hz}$ produced much smaller changes in fluorescence both for AP5-containing saline $(E)$ and control saline $(F)$. Images shown in $C$ and $D$ represent average fluorescence changes for $t=3.8-4.0$ sec after stimulation began. $G$ and $H$, Similar experiments were conducted in which furaptra was used as a ratio dye and pseudocolor images were formed from the change in the ratio of images excited at both $340 \mathrm{~nm}$ and $380 \mathrm{~nm}$. $G$, Fluorescence image of a cell filled with furaptra. Stimulus electrode placement is shown in red in the upper left. $H$, The AP5-sensitive component of fluorescence change produced by subtracting the $\Delta R / R$ image measured during 100 $\mathrm{Hz}$ stimulation in the presence of AP5 from the $\Delta R / R$ image measured during $100 \mathrm{~Hz}$ stimulation in control saline. Note the remarkably localized increase in divalent ion concentration. Scale bars, $200 \mu \mathrm{m}$. 

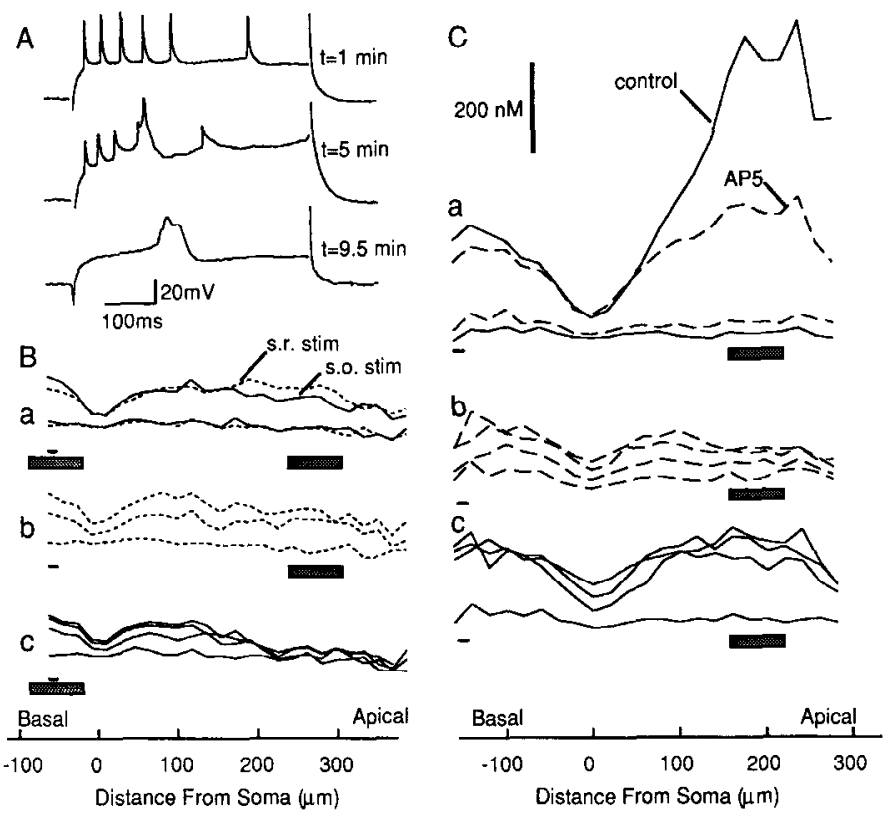

Figure 8. $\mathrm{Ca}^{2+}$ accumulations in the presence of QX-314. $A$, Intracellular recording made from a CA1 pyramidal cell with an electrode filled with $100 \mathrm{~mm} \mathrm{KCl}, 40 \mathrm{~mm}$ QX-314, and $14 \mathrm{~mm}$ fura-2. Spike amplitudes are attenuated due to the very high impedance electrodes used to fill cells and poor capacity compensation; resting potential, -60 $\mathrm{mV}$. After the first trace $(t=1 \mathrm{~min}),-1 \mathrm{nA}$ current was injected for 4 min, filling the cell to an estimated $100 \mu \mathrm{M}$ fura-2. After alternating $+0.5 \mathrm{nA}$ and $-0.5 \mathrm{nA}$ current pulses for an additional $4.5 \mathrm{~min}$, the fast $\mathrm{Na}^{+}$action potentials were blocked and depolarization produced a slow active response that we interpret to be a calcium action potential. $B$ and $C, \mathrm{Ca}^{2+}$ accumulation versus distance from the cell soma in response to synaptic stimulation via activation of inputs by a stimulus electrode positioned as indicated by the shaded rectangles. $B$, In the presence of AP5, two electrodes were used to activate the cell synaptically, one located in stratum oriens and one located in stratum radiatum. $B a$, The lower two traces show the resting $\mathrm{Ca}^{2+}$ levels prior to the stimulus train, and the upper two traces show the accumulations for $100 \mathrm{~Hz}$ stimulation $(t=0.2-0.9 \mathrm{sec}) . B b$. Accumulations produced by $20 \mathrm{~Hz}$ stimulation of stratum radiatum. The three traces are (for increasing amplitude) resting levels, $t=0.2-1.5 \mathrm{sec}$, and $t=1.7-2.7 \mathrm{sec}$. The stimulus train was on from $t=0$ to $t=5 \mathrm{sec}$, but subsequent $\mathrm{Ca}^{2+}$ accumulations were reduced in amplitude. $B C$, Accumulations produced by $20 \mathrm{~Hz}$ stimulation of stratum oriens. The four traces are (for increasing amplitude) resting levels, $t=0.2-1.5 \mathrm{sec}, t=1.7-2.7 \mathrm{sec}$, and $t=2.9-3.9 \mathrm{sec} . C, \mathrm{Ca}^{2+}$ accumulations for stratum radiatum $100 \mathrm{~Hz}$ stimulation in control saline and in the presence of AP5 (a), $20 \mathrm{~Hz}$ stimulation in AP5-containing saline $(b)$, and $20 \mathrm{~Hz}$ stimulation in control saline $(c)$. Successive traces in $b$ and $c$ are as follows: rest, $t=0.2-1.5 \mathrm{sec}, t=1.7-2.7 \mathrm{sec}$, and $t=$ 2.9-3.9 sec. Concentration calibration in $C$ refers to $B$ and $C$.

volved in the induction of LTP. We focused on several issues raised by previous studies. First, do Na channels influence AP5sensitive calcium transients? Second, what is the effect of stimulus intensity on these accumulations?

Studies by Barrionuevo and Brown (1983) demonstrated that the presence of the local anesthetic QX-314, which blocks $\mathrm{Na}^{+}$ channels from the inside of the cell membrane without significantly affecting $\mathrm{Ca}^{2+}$ currents or glutamate-activated currents (Bernardo et al., 1982), did not prevent the induction of LTP. This observation, combined with the calcium induction hypothesis, suggests that AP5-sensitive $\mathrm{Ca}^{2+}$ accumulations should not be greatly reduced by QX-314.

We found that injection of QX-314 into the postsynaptic cell did not greatly alter the magnitude or spatial distribution of AP5-sensitive $\mathrm{Ca}^{2+}$ accumulations ( $n=5$; Fig. 8). QX-314 elim-
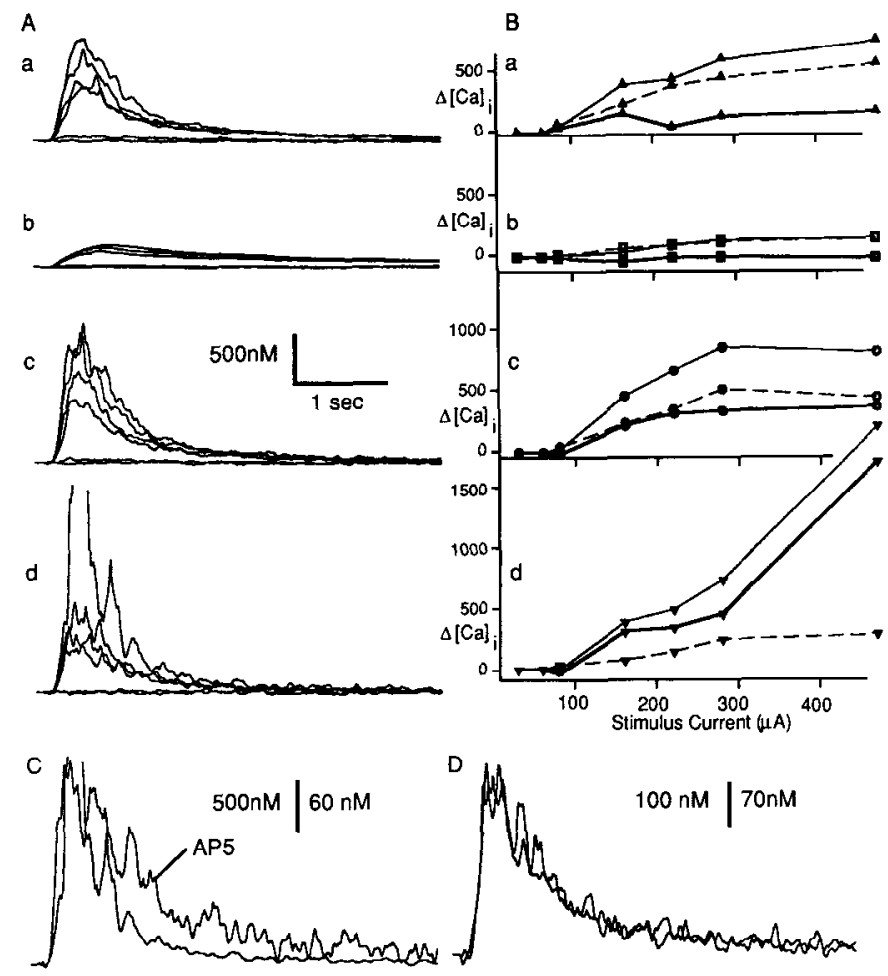

Figure 9. Dependence of $\mathrm{Ca}^{2+}$ accumulation amplitude on stimulus intensity levels $(60 \mu \mathrm{A}, 80 \mu \mathrm{A}, 160 \mu \mathrm{A}, 220 \mu \mathrm{A}, 280 \mu \mathrm{A}, 470 \mu \mathrm{A}) . A$, Calcium transients were measured in response to stimulation of stratum radiatum at $100 \mathrm{~Hz}$ for $1 \mathrm{sec}$ at different intensities in basal dendrites $(a)$, soma $(b)$, proximal-apical dendrites $(c)$, and distal-apical dendrites (d). The stimulus electrode was located in the distal-apical dendrites. $B$, Corresponding peak calcium accumulations versus stimulus current for control saline (thin solid line), AP5-containing saline (dashed line), and the difference between AP5 and control saline (thick solid line) for basal dendrites $(a)$, soma $(b)$, proximal-apical dendrites $(c)$, distal-apical dendrites $(d)$. $C$, Comparison of accumulations in distal-apical dendrites for AP5 and control saline for the same stimulus intensity plotted on different scales to compare time courses (470 $\mu \mathrm{A}$ stimulus). $D$, Comparison of accumulations in distal-apical dendrites for AP5 and control saline at different stimulus intensity plotted on different scales to compare time courses (470 $\mu \mathrm{A}$ stimulus for AP5, $160 \mu \mathrm{A}$ stimulus for control). In $C$ and $D$, calibration to the left refers to control saline and calibration to the right refers to AP5-containing saline.

inated $\mathrm{Na}^{+}$spikes, and the cell responded to depolarization with a prolonged action potential typical of a $\mathrm{Ca}^{2+}$ spike (see Fig. $8 A$ ). Blocking $\mathrm{Na}^{+}$channels with QX-314 did not greatly affect AP5-insensitive accumulations produced by $100 \mathrm{~Hz}$ stimulation (Fig. $8 \mathrm{Ca}$; see also Table 1 , line 7 b). For $20 \mathrm{~Hz}$ stimulation, small AP5-sensitive accumulations were observed. Under $\mathrm{Na}^{+}$ channel block by QX-314, AP5-insensitive accumulations were reduced in amplitude (Fig. $8 C b, c$; Table 1 , line $8 \mathrm{~b}$ ), and this facilitated the observation of AP5-sensitive accumulations at moderate frequency $(20 \mathrm{~Hz})$.

The induction of LTP depends critically on the number of stimulated afferents. If the stimulus intensity is not sufficiently strong, no long-lasting potentiation occurs. How does the AP5sensitive component of $\mathrm{Ca}^{2+}$ accumulation depend upon the stimulus intensity?

To determine how increasing stimulus amplitude affected AP5sensitive $\mathrm{Ca}^{2+}$ accumulations, a prepotentiating train was first used to ensure that subsequent test trains would not induce LTP. Then, $\mathrm{Ca}^{2+}$ accumulations were measured in response to stimulation by different-amplitude stimulus trains in both control 

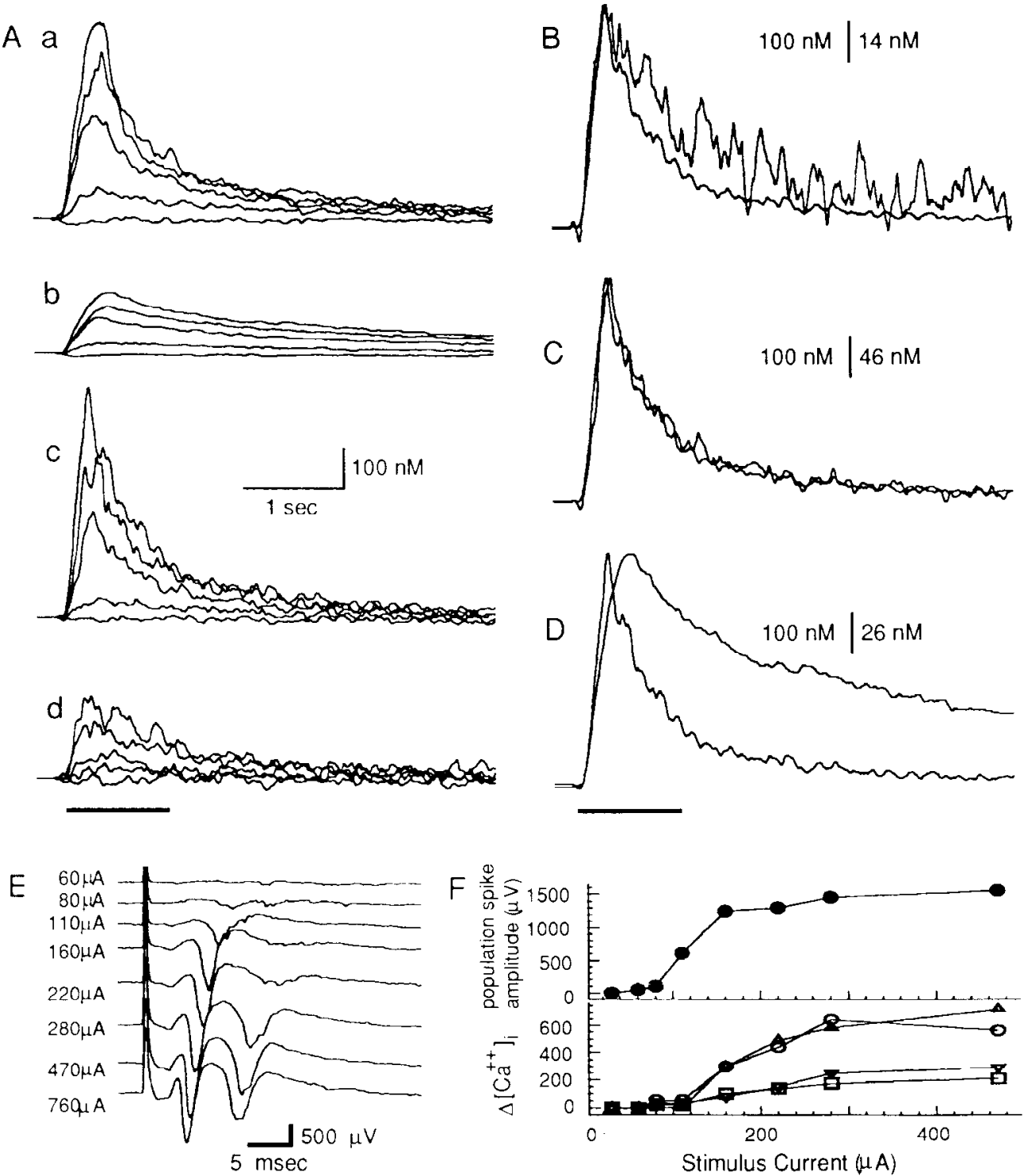

Figure 10. Dependence of $\mathrm{Ca}^{2+}$ accumulation amplitude on stimulus intensity in the presence of AP5. A, Calcium transients were measured in response to stimulation of stratum radiatum at $100 \mathrm{~Hz}$ for $1 \mathrm{sec}$ at different intensities $(60 \mu \mathrm{A}, 80 \mu \mathrm{A}, 160 \mu \mathrm{A}, 220$ $\mu \mathrm{A}, 280 \mu \mathrm{A})$ in basal dendrites $(a)$, soma (b), proximal-apical dendrites (c), and distal-apical dendrites $(d)$. $B$ and $C, \mathrm{Ca}^{2+}$ accumulation for peak stimulation in the proximal-apical dendrites is plotted with lower-amplitude $\mathrm{Ca}^{2+}$ accumulations in the same dendritic regions. Calibration to the left refers to accumulations occurring for the larger stimulus current $(280 \mu \mathrm{A})$, and calibration to the right refers to $\mathrm{Ca}^{2+}$ accumulations in response to lower-amplitude stimulus $(B: 60 \mu \mathrm{A}$, noisy trace; $C: 110 \mu \mathrm{A}) . D$, $\mathrm{Ca}^{2+}$ accumulations occurring in response to the same stimulus train for the soma and proximal-apical dendrite. Calibration to the left refers to the proximal-apical dendrite, and calibration to the right refers to the soma $(280 \mu \mathrm{A}$ stimulation). $E$, Field potential measurements of the population spike measured in stratum pyramidal produced by a $0.2 \mathrm{~Hz}$ test pulse at the indicated stimulus intensities. $F$, The upper plot is of the amplitude of the population spike measured from the traces in $E$, and the lower plot shows the peak calcium accumulations as a function of stimulus intensity for the basal dendrites (upright triangles), the soma (squares), the proximal-apical dendrites (circles), and the distal-apical dendrites (inverted triangles). and AP5-containing saline. Accumulations in control saline for the set of increasing stimulus amplitudes are shown for the basal dendrites, the soma, proximal apical dendrites, and the distal apical dendrites (Fig. 9A). For very large stimuli, peak $\mathrm{Ca}^{2+}$ levels saturated the fluorophore $\left(\left[\mathrm{Ca}^{2+}\right]_{i}\right.$ levels higher than several micromolar) in the spatially averaged distal-apical dendrite region that corresponded most closely to the location of the stimulating electrode. The peak accumulations in control saline, AP5-containing saline, and the difference between accumulations in control saline and AP5-containing saline (control-AP5) at each of the four cellular locations are shown in Figure $9 \mathrm{Ba}-$ $d$ as a function of stimulus amplitude.

We investigated the possibility that the differences in time course of AP5-sensitive and -insensitive components might reflect differences in the location of calcium influx producing these accumulations. For the same stimulus amplitude, accumulations in AP5 and control saline decayed with different time courses, as shown in Figure $9 C$. The difference in shape between the decay of accumulations in AP5-containing and control saline could reflect differences in the decay kinetics of two different pools of $\mathrm{Ca}^{2+}$ (such as might occur if VDCC accumulations were on the dendrites and NMDA receptor-mediated accumulations occurred on spines) or might simply reflect differences in the time course of return to resting levels that result from different initial amplitudes of accumulation. When stimulus intensities were adjusted to produce the same amplitude $\mathrm{Ca}^{2+}$ accumulation in control and AP5-containing saline, the time course of return to resting levels for both conditions was indistinguishable (Fig. 9D). Thus, differences in the time course of recovery in Figure $9 C$ are a result of differences in $\left[\mathrm{Ca}^{2+}\right]_{i}$ level reached during stimulation (see Discussion).

\section{Further characterization of the AP5-insensitive calcium accumulations}

To characterize further the AP5-insensitive calcium accumulations, we have examined the effects of (1) increasing stimulus electrode intensity, (2) pharmacological alteration of voltagedependent calcium channels by $\mathrm{Cd}^{2+}$ and dihydropyridines, (3) sodium channel block by intracellular QX-314, (4) the geometry of stimulating electrode placement, and (5) block of GABA receptor-mediated inhibition with PTX. 
We measured $\mathrm{Ca}^{2+}$ accumulations produced by a series of stimulus trains of increasing current strengths in the presence of AP5 in order to relate the amplitude of the population spike (Fig. 10E) to the amplitude of $\mathrm{Ca}^{2+}$ accumulations (Fig. 10A), and to compare temporal aspects of $\mathrm{Ca}^{2+}$ accumulations for different cell regions (Fig. $10 D$ ) and for different amplitude accumulations in the same dendritic region (Fig. 10B,C). Increasing stimulus strength produced a graded increase in both $\mathrm{Ca}^{2+}$ accumulations and population spike amplitude that eventually saturated at high stimulus intensities (Fig. 10F). For large and small amplitude accumulations, the return to resting levels followed different time courses (Fig. 10B). However, the larger amplitude accumulations observed within a given region followed the same time course as medium amplitude accumulations within the same dendritic region (Fig. 10C). Typically for very small amplitude accumulations it was possible to approximate the accumulations with a single exponential in the range $\tau=2-4 \sec$ (although typically the signal-to-noise ratio was rather poor). It was not possible to fit larger amplitude accumulations with single exponentials, and for Figure $10 \mathrm{C}$ the accumulations are better fit by a double exponential decay similar to that shown in Figure $6 D$. For the soma, a very different time course of accumulation was observed. This is demonstrated in Figure $10 D$. It takes longer for $\left[\mathrm{Ca}^{2+}\right]_{i}$ to peak in the soma than in the dendrites and longer for the calcium to return to resting levels.

To determine the source of the AP5-insensitive accumulations observed in hippocampal pyramidal cells, we tested their pharmacological sensitivity. Afferent fiber stimulation was not used since it would be impossible to distinguish between presynaptic and postsynaptic effects. One approach to this problem would have been to use intracellular electrode methods, for example, single-electrode voltage clamp, to depolarize the cell and to measure the resulting $\mathrm{Ca}^{2+}$ accumulations with imaging; this would provide controlled manipulation of membrane potential, but would require long-duration intracellular penetration (to allow for washin and washout of pharmacological agents) and suffer from space-clamp difficulties. Instead, we filled individual neurons with fura-2, removed the intracellular electrode, and then used an extracellular electrode to stimulate the neuron antidromically to fire action potentials in antagonistfree saline, repeated in agonist-containing saline, and then switched back to agonist-free saline. This allowed long-duration (several hours), stable $\left[\mathrm{Ca}^{2+}\right]_{i}$ measurements, without requiring a stable intracellular penetration. It did not allow manipulation of the intracellular membrane potential of the cell. To accentuate accumulations produced by changes in intracellular membrane potential accompanying antidromic spike invasion and to minimize synaptically mediated responses, experiments were performed in $50 \mu \mathrm{M}$ APV (NMDA glutamate receptor antagonist), $5 \mu \mathrm{M}$ 6-cyano-7-dinitroquinoxaline-2,3-dione (CNQX; Honore et al., 1988; non-NMDA glutamate receptor antagonist), and

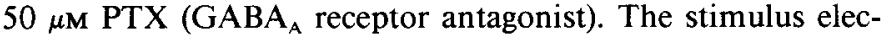
trode was placed in the alveus and a field potential electrode was placed near the imaged cell soma to monitor evoked response amplitude.

Based upon extensive evidence for the presence of $\mathrm{Ca}^{2+}$ channels in hippocampal pyramidal cells, it was likely that influx through these channels was at least partly responsible for the observed AP5-insensitive $\mathrm{Ca}^{2+}$ accumulations. While there is some dispute as to the number of VDCC types present in adult hippocampal pyramidal neurons, there is general agreement that 200-500 $\mu \mathrm{M} \mathrm{Cd}^{2+}$ (somewhat lower concentrations are effective for cultured neurons) provides essentially a complete block of all VDCC influx. $\mathrm{Cd}^{2+}$ at $500 \mu \mathrm{M}$ reduced the accumulations to $20 \%$ of those measured in control saline $(n=7$; Fig. $11 B)$.

We also determined the effects of the dihydropyridines nifedipine and Bay-K 8644, and of $\omega$-conotoxin on the AP5sensitive accumulations (Fig. 11). Nifedipine has been shown to reduce significantly, and Bay-K 8644 to increase greatly, influx through L-type $\mathrm{Ca}^{2+}$ channels (see Bean, 1989, for a review). Although these compounds are light sensitive, their use is compatible with $\mathrm{Ca}^{2+}$ imaging experiments using fura-2 (Hockberger et al., 1989). In the presence of Bay-K $8644(10 \mu \mathrm{M}), \mathrm{Ca}^{2+}$ accumulations were $61 \%$ larger than in control saline $(n=5$; Fig. $11 C)$. In the presence of nifedipine $(10 \mu \mathrm{M})$, transients were reduced by $31 \%$ compared to those in control saline ( $n=6$; Fig. $11 D)$. The snail toxin $\omega$-conotoxin $(10 \mu \mathrm{M})$ blocked $30 \%$ of the accumulations ( $n=2$; data not shown; no recovery was observed following a $30 \mathrm{~min}$ washout). The sensitivity of these measurements was not sufficient to resolve reliably the specific effects on the spatial distributions of the $\mathrm{Ca}^{2+}$ accumulations for Bay-K 8644 and nifedipine (Fig. 11 Ca, Da). Our combined results on the effects of $\mathrm{Cd}^{2+}$, nifedipine, and Bay-K 8644 suggested that AP5-insensitive calcium accumulations were to a large degree produced by influx through VDCC (but see Discussion).

How does the location of synaptic input influence the AP5sensitive $\mathrm{Ca}^{2+}$ accumulations? In a given dendritic region, influx through VDCC depends on both the channel density and the depolarization of those VDCCs. If synaptic currents were primarily responsible for providing the depolarization of VDCC, with active conductances providing little additional depolarizing current, one would predict that influx through VDCCs would be greatest in sites electrically close to the site of synaptic input.

AP5-sensitive accumulations were, however, primarily confined to the proximal-apical and the basal dendrites for a variety of stimulus conditions. This spatial profile was observed for afferent fiber stimulation in stratum oriens, proximal stratum radiatum, distal stratum radiatum, and stratum moleculare (Fig. 12); antidromic stimulation (Fig. 11 $A$ ); and intracellular depolarization (Regehr et al., 1989). Even stimulation of fibers synapsing on distal-dendritic regions produced AP5-insensitive $\mathrm{Ca}^{2+}$ accumulations that peaked in proximal dendrites $(n=6)$.

However, the location of synaptic activation did have a small influence on the distribution of accumulations. This can be seen in the images of Figure $12 C-F$. The effect is most easily observed by considering the accumulations in the distal-apical dendrite in the plot of $\mathrm{Ca}^{2+}$ concentration versus distance for the peak $\mathrm{Ca}^{2+}$ accumulations (Fig. 12G). When the stimulus electrode was placed in stratum oriens, $\mathrm{Ca}^{2+}$ accumulations observed in distal-apical dendrites were generally smaller than those observed with the stimulus electrode placed on the other side of the soma ( 10 cells).

The relatively minor importance of the position of afferent fiber activation raises an important question. Are AP5-sensitive $\mathrm{Ca}^{2+}$ accumulations higher in proximal dendrites due to a higher density of VDCC in these regions, or is the observed spatial distribution a result of preferential activation of VDCC by active conductances in proximal dendrites?

The contribution of $\mathrm{Na}$ channels to AP5-insensitive accumulations was tested by blocking $\mathrm{Na}$ channels intracellularly with QX-314. AP5-insensitive calcium transients were sub- 
A a

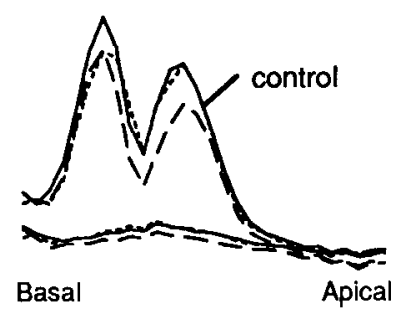

b

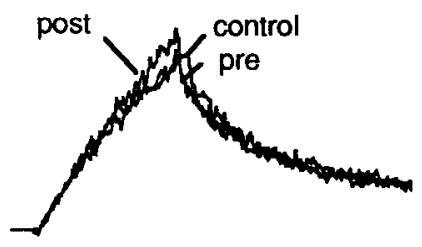

c

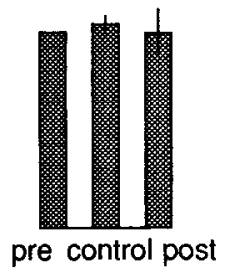

B a

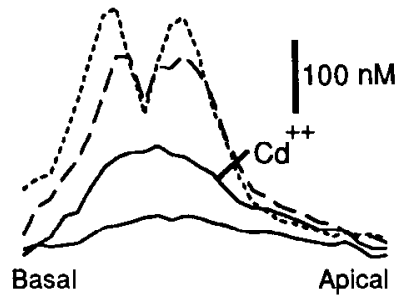

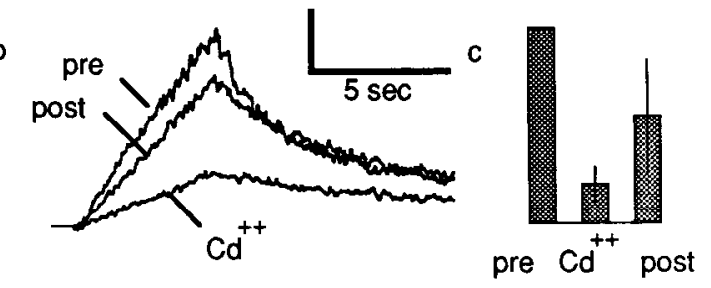

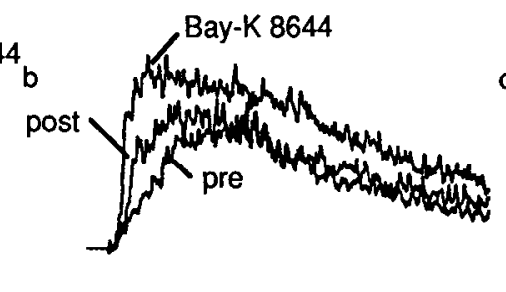

Basal
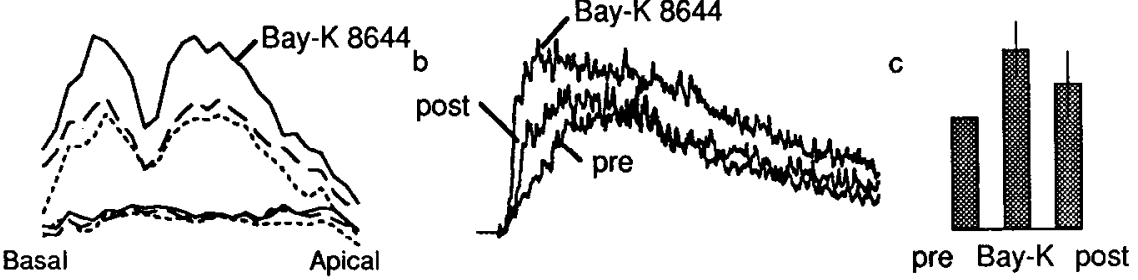

D a

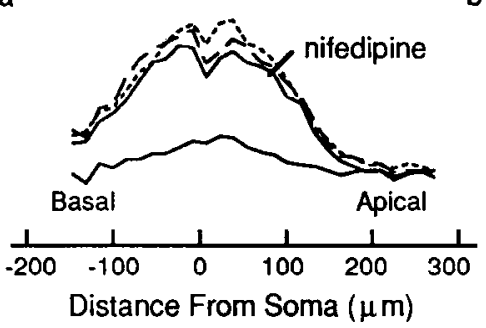

b

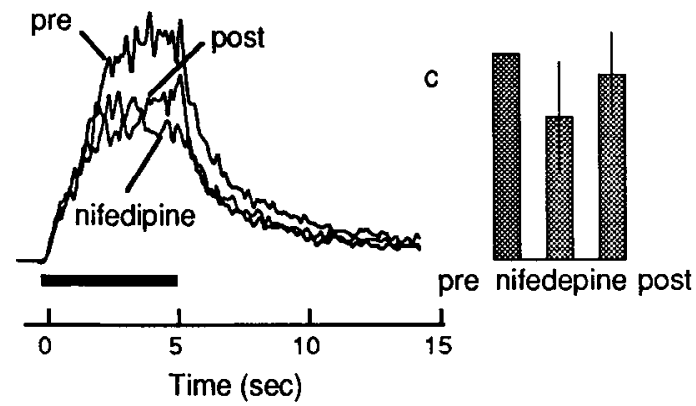

Figure 11. Summary of the pharmacological effects of nifedipine, $\mathrm{Cd}^{2+}$, and Bay-K 8644 on the spatial dependence and time course of AP5-insensitive accumulations produced by $5 \mathrm{sec}, 20 \mathrm{~Hz}$ antidromic stimulation. Three trials were performed for each cell, with trial 1 occurring at $t=0 \mathrm{~min}$, trial 2 at $t=$ $30 \mathrm{~min}$, and trial 3 at $t=60 \mathrm{~min}$. The solution was changed to the test solution immediately following trial 1 and then switched back to control saline immediately following trial 2. $a$, Spatial distribution of $\mathrm{Ca}^{2+}$ accumulations. Calibration in $B a$ refers to $A a-D a$. Fine dashed line represents control at $t=0$; solid line, $t=30 \mathrm{~min}$ (test condition); and the other dashed line, the control response after washout. $b$, Time dependence of $\mathrm{Ca}^{2+}$ accumulations in the proximal dendrites. $c$, Histogram of accumulation amplitudes. Values represent the peak accumulations, except for $B a y \cdot K$ where, for all three cases, it represents average accumulation during the period $(1-2 \mathrm{sec}) . A$, All three trials in control saline; $B, 50 \mu \mathrm{M} \mathrm{Cd} \mathrm{Cd}^{2+} ; C, 10 \mu \mathrm{M}$ Bay-K 8644; $D, 10 \mu \mathrm{M}$ nifedipine. Concentration calibration in $B b$ refers to $\mathrm{Ca}^{2+}$ concentration: $100 \mathrm{~nm}$ for $A b, 100$ nм for $B b, 75 \mathrm{~nm}$ for $C b$, and $130 \mathrm{~nm}$ for $D d$. stantially reduced in amplitude, particularly for $20-\mathrm{Hz}$ stimulation (see Fig. 8B, $C$, Table 1, and Discussion). In addition QX-314 strongly influenced the spatial profile of AP5-sensitive calcium accumulation. Differences between accumulations in proximal and distal regions became less pronounced with $\mathrm{QX}$ 314 inside the cell (sce Fig. $8 B, C$ and compare that to spatial profiles for control cell; also see the discussion for implications of these experiments in regard to the cause of the observed spatial distribution of calcium accumulation).

To test whether GABA $_{A}$ receptor-mediated inhibition influences the spatial pattern of accumulations, several experiments were performed in the presence of PTX (Table 1, lines 9, 10). Synaptic activation with a stimulus electrode located in distal stratum radiatum produced $\mathrm{Ca}^{2+}$ accumulations in PTX-containing saline and AP5 + PTX-containing saline that were qualitatively similar to accumulations observed without the PTX. For both $20 \mathrm{~Hz}$ and $100 \mathrm{~Hz}$ stimulation, an AP5-insensitive accumulation was produced in the distal dendrites, and for 100 $\mathrm{Hz}$ stimulation a large AP5-sensitive accumulation was produced in synaptically activated dendritic regions. This indicates that $\mathrm{GABA}_{\mathrm{A}}$-mediated inhibition does not contribute to the observed spatial pattern of accumulation.

\section{Discussion}

We have measured synaptically evoked calcium accumulations in individual hippocampal CA 1 pyramidal cells for a variety of experimental conditions. We will first summarize general features of the spatial pattern and time course of these accumulations and suggest implications for cellular processes in which $\mathrm{Ca}$ acts as a second messenger. Two broad areas are discussed: ion channel modulation and the induction of LTP. The biophysical mechanisms that underlie the observed patterns and time courses of calcium accumulation are then considered. We finish by commenting upon precautions we have followed that are necessary to eliminate artifacts and errors in the use of optical indicators such as fura- 2 in brain slice preparations.

\section{Implications for second messenger actions of calcium}

Modulation of ionic conductances. The synaptically activated $\left[\mathrm{Ca}^{2+}\right]_{i}$ dynamics that we have measured constrain the duration, spatial location, and amplitude of the $\mathrm{Ca}^{2+}$ signal available to act as a second messenger in CA1 hippocampal pyramidal cells. This has consequences for the modulation of the wide variety of $\mathrm{Ca}^{2+}$-sensitive conductances. This includes voltage-depen- 
A

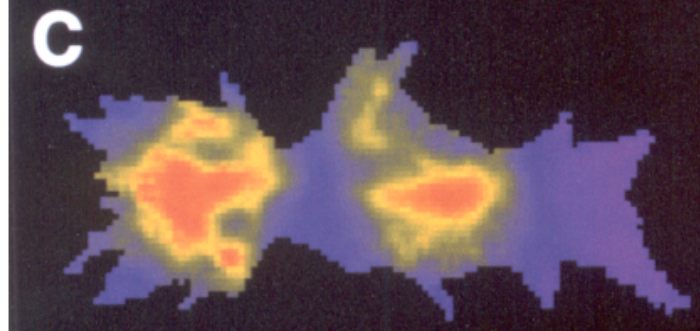

E

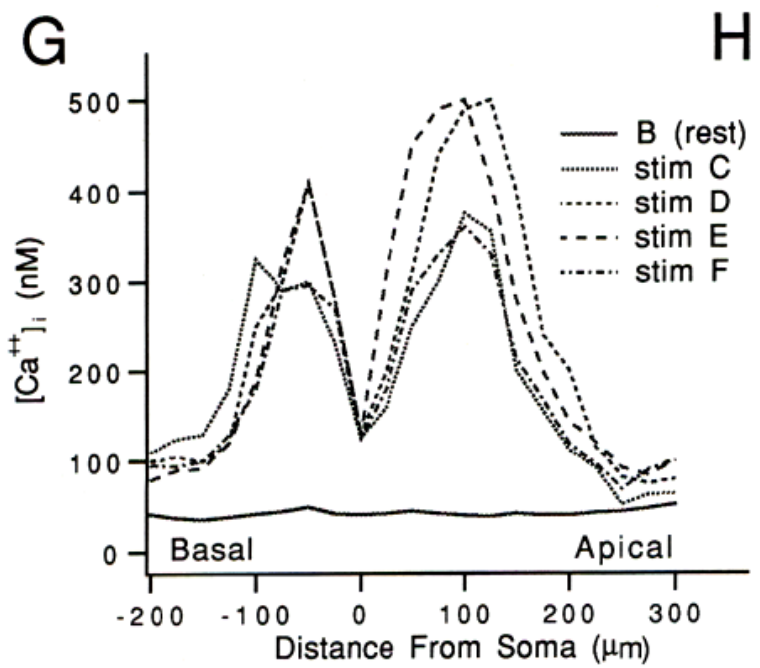

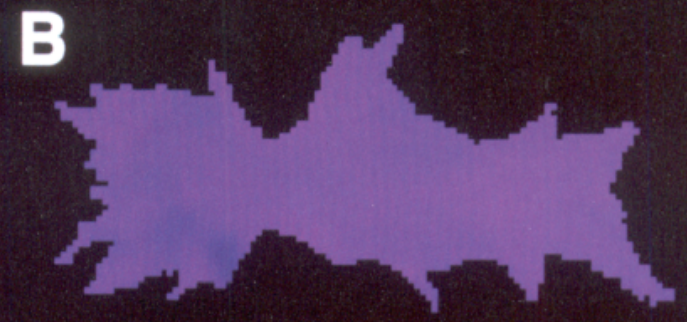

$\mathrm{nM}$

$-800$

D

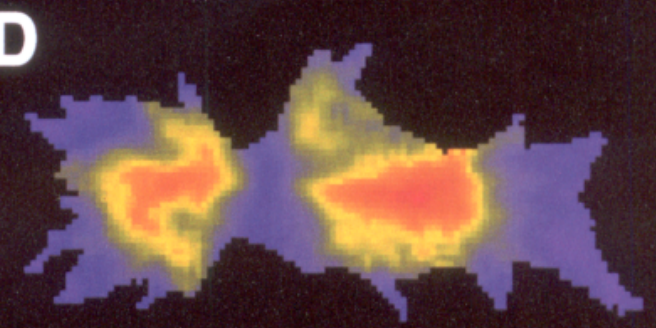

$-500$

$-250$

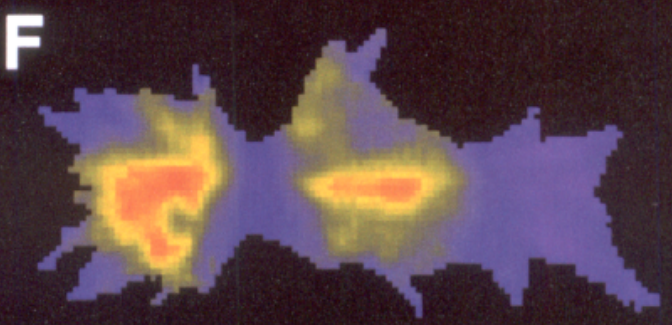

$\left[\mathrm{Ca}^{2+}\right]_{\mathrm{i}}$

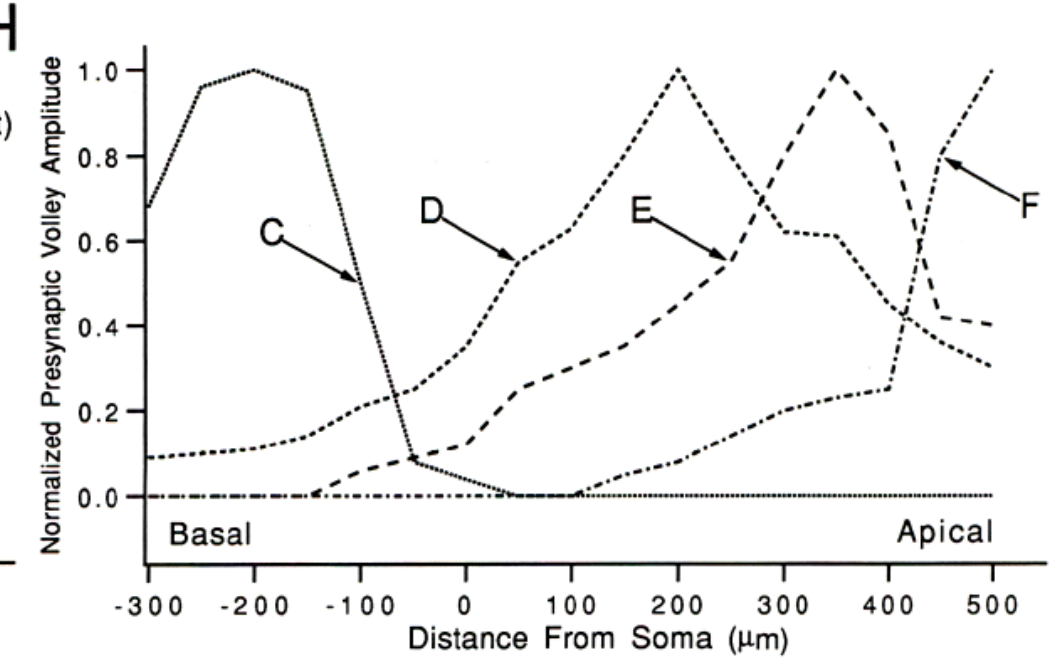


dent $\mathrm{K}^{+}$current $\left(I_{C}\right)$ involved with rapid repolarization, a voltage-independent $\mathrm{Ca}^{2+}$-dependent $\mathrm{K}^{+}$current $\left(I_{A H P}\right)$ responsible for accommodation (Adams et al., 1982; Lancaster and Nicoll, 1987; Williamson and Alger, 1990), and nonspecific cation channels (Partridge and Swandula, 1988). Acting through a $\mathrm{Ca}^{2+}$. dependent protein kinase, calcium can downregulate the inhibitory current of the $\mathrm{GABA}_{\mathrm{A}}$ receptor channel (Stelzer et al., 1988; Chen et al., 1990). $\mathrm{Ca}^{2+}$ can also inactivate $\mathrm{Ca}^{2+}$ channel conductances (Eckert and Chad, 1984; Kay, 1991).

The time course and amplitude of calcium-activated and calcium-modulated conductances in different cellular regions will reflect local calcium levels. This suggests that the activation of Ca-sensitive conductances will differ markedly in the soma and the dendrites due to the very different $\mathrm{Ca}$ transients in these regions. The relationship between $\mathrm{Ca}$ and channel activation is, however, complicated by factors such as involvement of second messengers, $\mathrm{Ca}$ affinity, proximity to $\mathrm{Ca}$ channels, and the kinetic properties of $\mathrm{Ca}$ channels. The effect of $\mathrm{Ca}$ affinity is illustrated by consideration of two types of $\mathrm{K}$ channels, $I_{A H P}$ and $I_{C}$, and how they would be activated in the soma and the dendrites.

The channels associated with $I_{A H P}$ are sensitive to relatively low levels of calcium (within the range of calcium transients we measured). Consequently, channels located on the surface membrane of proximal dendrites would be activated to a larger degree but for a much shorter time than those channels located on the soma.

$I_{C}$, which is less sensitive to residual free Ca levels and is thought to be activated primarily by the very high $\mathrm{Ca}$ levels that exist near the mouth of open calcium channels, would not be greatly influenced by the different time courses observed in bulk cytoplasm in different cellular compartments. The spatial dependence of its activation would be more influenced by the spatial dependence of active calcium channels and the proximity, on the submicrometer scale, between $I_{C}$ channels and calcium channels. Thus, in contrast to $I_{A H P}$, the measurements presented here shed little light on $I_{C}$ activation.

In response to tetanic activation, our measurements show that calcium accumulates to levels that have been shown to inactivate calcium channels in hippocampal CAl pyramidal cells (Kay, 1991). This inactivation is generally not complete, but $1 \mu \mathrm{M}$ $\left[\mathrm{Ca}^{2+}\right]_{i}$ can reduce $\mathrm{Ca}^{2+}$ current to one-third of its value at low $\mathrm{Ca}^{2+}$ levels. This form of negative feedback tends to self-limit the maximum calcium accumulations that can be produced by influx through VDCC. Interestingly, the largest calcium accumulations that we have observed that can be attributed to VDCC are in the low micromolar range.

The spatial pattern and time course of calcium accumulations we have measured may also produce a spatial and temporal modulation of $\mathrm{GABA}_{\mathrm{A}}$-mediated inhibition (Stelzer et al., 1988; Chen et al., 1990), since increased postsynaptic $\left[\mathrm{Ca}^{2+}\right]_{i}$ reduces the magnitude of this form of synaptic inhibition.

Induction of long-term potentiation. The large calcium ac- cumulations localized to regions postsynaptic to activated afferent fibers that we observed in response to $100 \mathrm{~Hz}$ stimulation provide direct evidence for an AP5-sensitive pool of calcium available to induce LTP. In all cases we have examined, these accumulations are transient. For high-frequency stimulation, the buildup of AP5-sensitive calcium is rapid and the decay commences before the end of the stimulus train. Calcium levels recover to resting level on the seconds time scale. (Field potential recordings also show a diminished synaptic component during the commencement of calcium decay that occurs before the end of the stimulus train. We attribute this to a reduction in synaptic activation, as indicated by the reduction of the presynaptic volley, and to depression.)

We find no evidence for sustained elevation of calcium following the induction of LTP. We conclude that sustained calcium accumulations observed in acutely dissociated neurons in response to repeated NMDA application (Connor et al., 1988) do not occur during the induction of LTP. We suggest that although these phenomena may be produced by biochemical pathways involved with the induction of LTP, the sustained increases themselves do not occur under normal conditions and they are more appropriately considered as a model of cellular processes associated with excitotoxicity.

The rapidity of the calcium transients places limits on the duration of the calcium signal available to trigger LTP. In general, biochemical reactions of the type suggested for the induction of LTP depend both on the amplitude and duration of reactant levels. The amplitude and duration of the calcium signal required to activate the biochemical processes that induce LTP and the location of calcium-sensitive substrates have yet to be determined.

Previous estimates of the calcium levels sufficient to induce LTP were based upon experiments that used nitro- 5 to increase calcium throughout the postsynaptic cell (Malenka et al., 1988). In these experiments, it was necessary to introduce large concentrations of exogenous buffer. For such conditions, the decay of calcium would be slowed and it is likely that intracellular calcium remained elevated for tens of seconds to minutes (Tank, Delaney, and Regehr, unpublished observations), instead of decaying to resting levels with a very rapid time course. This disparity between the likely time course of artificially increased calcium and the time course we observe makes it impossible to estimate the calcium levels necessary to induce LTP under normal intracellular conditions.

While the calcium measurements described here do not allow direct comparison of calcium accumulations in spines and dendrites, they do provide information relevant to the issue of what calcium level is required to induce LTP. It has been proposed that spines and their associated calcium sequestration apparatus serve to separate pools of calcium, so that local calcium increases in an individual spine head can trigger the modification of its associated synaptic strength without affecting nearby spines (see review by Nicol et al., 1988). We observe that $20 \mathrm{~Hz}$ synaptic

\footnotetext{
Figure 12. Orthodromic synaptic activation of afferents synapsing on different dendritic regions produce similar calcium accumulations. For the cells whose $380 \mathrm{~nm}$-excited fluorescent image is shown in $A$, resting calcium levels were low and uniform $(B)$. Afferent fiber stimulation at $20 \mathrm{~Hz}$ for $5 \mathrm{sec}$ in the presence of AP5 produced large calcium accumulations. Pseudocolor images show the calcium accumulations for stimulus electrode located in stratum oriens $(C)$, proximal stratum radiatum $(D)$, distal stratum radiatum $(E)$, and stratum moleculare $(F)$. Images were taken in the last second of the image train. The spatial profiles of the calcium accumulations shown in $B-F$ are quantitatively compared in $G$, which is a plot of $\mathrm{Ca}^{2+}$ accumulations versus distance from the soma. $H$, The presynaptic volley amplitude versus distance from the cell soma for these four trials shown serves as a measure of the location of the afferent fiber input. Note that the dendrites extended well into stratum moleculare but that calcium levels in this region were not displayed because the signal-to-noise in this region was poor.
} 
activation in, for example, distal stratum radiatum produces calcium levels of about $1 \mu \mathrm{M}$ for many seconds in proximalapical and basal dendritic regions where, because of the homosynaptic specificity of LTP induction in CAl, no synaptic potentiation would be expected. This implies that if a postsynaptic calcium increase in a spine head is alone sufficient to induce LTP (Malenka et al., 1988), then the accumulations we measured were occurring only in the smooth dendrite areas and the spine apparatus effectively isolates spines from dendrites. Alternatively, the induction of LTP may require calcium levels substantially higher than $1 \mu \mathrm{M}$.

A comparison of calcium accumulations and the magnitude of potentiation produced by $20 \mathrm{~Hz}$ and $100 \mathrm{~Hz}$. stimulation produces puzzling results. While the amplitude of LTP generated by $20 \mathrm{~Hz}$ stimulation is only slightly smaller than that generated by $100 \mathrm{~Hz}$ stimulation, the difference between the AP5-sensitive component of calcium accumulation is striking. The frequency-dependent enhancement of calcium accumulations is, however, consistent with computer models of calcium transients in spines (Gamble and Koch, 1987; Holmes and Levy, 1990).

It may be possible to reconcile inconsistencies between the calcium accumulations and the magnitude of induced LTP. Perhaps induction, like transmitter release at the presynaptic terminal, is sensitive only to the very high calcium levels located near the mouth of open calcium-permeable channels (10-100 $\mu \mathrm{M})$. Spines are very small structures, but they are still capable of supporting a calcium gradient. High $\mathrm{Ca}$ levels near channel mouths would still exist even if the average $\left[\mathrm{Ca}^{2+}\right]_{i}$ in the spine produced by this flux does not build up to levels high enough to be clearly distinguished in our experiments as an AP5-sensitive component of accumulation.

Recently, two groups have observed that it is possible to produce long-term synaptic enhancement of Schaffer collateral inputs to the hippocampal CA1 region in the presence of AP5, either by stimulating at extremely high frequencies (Grover and Teyler, 1990) or by temporarily blocking potassium channel conductances (Aniksztejn and Ben-Ari, 1991). For the experiments described by Grover and Teyler, it appears that the potentiation observed at high frequencies is blocked by nifedipine, suggesting that an influx of calcium through $\mathrm{VDCC}$ in the postsynaptic cell triggers the induction of this form of enhancement. It is possible that these calcium accumulations could be produced either via influx through VDCC located on spine heads or by influx through VDCC on dendrites that then diffuses to the spine. Our calcium measurements allow us to analyze further these electrophysiological experiments and to suggest which of these two possibilities of calcium accumulation is more likely. Our experiments show that AP5-insensitive calcium accumulations in dendritic regions are larger and longer lasting for moderate-frequency stimulus trains, when calcium measurements are averaged over the entire dendritic region (i.e., spines and smooth dendrite). However, it is a high-frequency stimulus that produces AP5-insensitive LTP in the electrophysiology experiments, so we suggest that the influx that produces this form of LTP occurs on the spine head. Thus, our measurements of AP5insensitive calcium accumulations in dendritic regions combined with recent experimental observations from other groups suggest that VDCCs are located on spinc hcads and that calcium influx through these channels can, under certain experimental conditions, produce calcium accumulations sufficient to induce LTP. Furthermore, our results predict that the magnitude of
AP5-insensitive LTP would be very small for inputs to distalapical dendritic regions where VDCC density is lower (assuming that VDCC densities on spine heads from different regions reflect differences in the average VDCC density for dendritic regions; see below).

\section{Source of calcium accumulations}

Intracellular calcium concentration is locally determined by the competing effects of the net influx and efflux as well as the calcium buffer characteristics. The two types of channels that are most likely to contribute to the transmembrane calcium influx are VDCC and NMDA receptor-coupled channels.

VDCCs in hippocampal pyramidal cells have been characterized using a variety of techniques and preparations (Schwartzkroin and Slawsky, 1977; Wong and Prince, 1978; Wong et al., 1979; Gahwiler and Brown, 1987; Kay and Wong, 1987; Yaari et al., 1987; Westenbroek et al., 1990). While there is some dispute as to the details of these conductances, such as the number of $\mathrm{Ca}^{2+}$ channel types present, there is general agreement that a prominent component of $\mathrm{Ca}^{2+}$ current is carried by high-threshold noninactivating $\mathrm{Ca}^{2+}$ channels that are enhanced by BAY-K 8644 and reduced by nifedipine.

Excitatory synaptic transmission onto CAl hippocampal pyramidal cells is primarily mediated through glutamate receptorcoupled ion channels. The NMDA receptor channel subtype is $\mathrm{Ca}^{2+}$ permeable (MacDermott et al., 1986), while non-NMDA receptor-coupled glutamate ion channels that mediate fast postsynaptic potentials have much lower Ca permeabilities (Iino et al., 1990).

Although we will focus on the contributions to calcium influx produced by the above two classes of calcium-permeable ion channels, it is important to keep in mind that other sources of calcium influx could potentially contribute to the accumulations. One possibility is internal release from intracellular stores (Berridge and Irvine, 1984; Lipscombe et al., 1988). Activation of a glutamate receptor coupled to inositol metabolism could potentially induce release from one of these pools (Sugiyama et al., 1987). If intracellular sodium levels become large, net calcium influx can also occur through the reversal of the $\mathrm{Na}^{+} / \mathrm{Ca}^{2+}$ exchange (Allen et al., 1989; Leblanc and Hume, 1990). $\mathrm{Ca}^{2+}$ influx can also occur at channel types other than VDCC and NMDA receptor-coupled ion channels, although the $\mathrm{Ca}^{2+}$ permeabilities are generally relatively small. Since at present we have no evidence for the involvement of any of these alternative sources of calcium accumulation, we will not discuss them further, although we cannot exclude a contribution from these sources.

Spatial differences in calcium buffering and uptake/extrusion mechanisms would complicate any attempt to relate calcium accumulation to calcium influx. Large variations in buffer concentration would alter the time course of calcium transients (Tank, Delaney, and Regehr, unpublished observations) (see Fig. $6 D$ ). Since all regional variations in the time course of calcium transients can be explained by geometrical differences (Fig. 6D, and see below), we will assume that buffering and sequestration in different dendritic regions are similar.

Our ability to attribute a given amount of calcium influx quantitatively to particular channel types is also compromised by the difficulty in dccoupling calcium influx through a particular channel type from influx through other channel types. For example, QX-314 not only blocks influx ( $\mathrm{Na}$ and $\mathrm{Ca}$ ) through sodium channels but also influences influx through calcium 
channels indirectly by modifying the depolarization of these channels.

Keeping these qualifications in mind, we discuss first the source of the AP5-sensitive and -insensitive accumulations, and then subsequently, we discuss the spatial dependence of the accumulations.

Source of AP5-sensitive $\mathrm{Ca}^{2+}$ accumulations. Given the demonstrated calcium permeability of the NMDA receptor-coupled ion channel (MacDermott et al., 1986), it is likely that at least part of the AP5-sensitive component of $\mathrm{Ca}^{2+}$ accumulation we have measured is produced by calcium influx through NMDA receptor channels. AP5 blockade of the NMDA receptor also decreases the depolarization of the postsynaptic cell, potentially affecting influx through VDCC. Thus, ionic flux through NMDA receptor channels was necessary to produce a large transient calcium accumulation postsynaptic to activated afferent fibers, but it is not possible to determine the relative contribution of $\mathrm{Ca}^{2+}$ influx through NMDA receptor channels and influx through VDCC to the AP5-sensitive accumulations from our experiments. Experimental obstacles that must be overcome before determining these contributions are the inability to voltage clamp an extensive structure such as a hippocampal pyramidal cell, and the lack of a VDCC blocker that acts selectively on postsynaptic $\mathrm{Ca}^{2+}$ channels without affecting NMDA channels, or release of neurotransmitter.

Source of AP5-insensitive $\mathrm{Ca}^{2+}$ accumulations. Our experimental results suggest that AP5-insensitive accumulations are largely produced by influx through VDCC since they were greatly reduced in the presence of $\mathrm{Cd}^{2+}$. The reduction of accumulations in the presence of nifedipine, and enhancement of accumulations in the presence of Bay-K 8644 demonstrate that $\mathrm{Ca}^{2+}$ influx through L-type VDCC contributes to these accumulations. These results do not exclude the possibility that influx through other types of VDCC accumulations could contribute to the AP5-insensitive accumulations (Fisher et al., 1990). Our results are in qualitative agreement with the pharmacological sensitivity of $\mathrm{Ca}$ currents in hippocampal pyramidal cells (Regan et al., 1991).

$\mathrm{Cd}^{2+}$ did not completely block all of the accumulations. For some types of calcium channels, the $\mathrm{Cd}^{2+}$ block of Ca channels is voltage dependent, such that while the current during positive voltage steps is eliminated, the tail currents observed upon repolarization are not completely eliminated. This may contribute to the accumulations in the presence of $\mathrm{Cd}^{2+}$. The AP5/ $\mathrm{Cd}^{2+}$ insensitive accumulation could potentially be due to several other sources. It is possible that influx through voltage-gated $\mathrm{Na}^{+}$channels could increase intracellular $\mathrm{Na}^{+}$sufficiently to either reverse the $\mathrm{Na}^{+} / \mathrm{Ca}^{2+}$ exchanger (Langer, 1980; Noble, 1980; Leblanc and Hume, 1990) and pump $\mathrm{Na}^{+}$out of the cell and $\mathrm{Ca}^{2+}$ into the cell, or to induce sodium-activated rclcasc (Leblanc and Hume, 1990). Also, $\mathrm{Ca}^{2+}$ influx directly through voltage-gated $\mathrm{Na}^{+}$channels could contribute to the observed accumulations. Since the relative permeability of TTX-sensitive $\mathrm{Na}^{+}$channels has been reported to about $P_{\mathrm{Ca}} / P_{\mathrm{Na}}=0.01$ for a variety of preparations, it is likely that such a contribution would be rather small.

It should be noted that the use of divalent blockers such as $\mathrm{Cd}^{2+}$ is in many cases incompatible with fura- 2 imaging. These ions can in some cases quench the fura- 2 fluorescence, and in other cases they can mimic calcium binding to fura-2. In these experiments, it is unlikely that fluorescence changes in the presence of $\mathrm{Cd}^{2+}$ are an artifact caused by $\mathrm{Cd}^{2+}$ passing through
VDCCs and binding to fura-2, which does have a finite affinity for most divalent cations including $\mathrm{Cd}^{2+}$. The decay of fluorescence transients follow the same time course whether or not $\mathrm{Cd}^{2+}$ is present, and it is highly unlikely that $\mathrm{Ca}^{2+}$ buffering and pumping systems would remove $\mathrm{Cd}^{2+}$ with the same time course as $\mathrm{Ca}^{2+}$.

\section{Spatial distribution of calcium accumulations}

AP5-sensitive accumulations. The AP5-sensitive accumulations are primarily localized to dendritic regions postsynaptic to activated afferent fibers. These accumulations are generally very large, and for high-frequency stimulation, often essentially no fluorescence is observed for $380 \mathrm{~nm}$ excitation, implying the fura- 2 is saturated. Since our photodetectors record from both dendrites and spines (which comprise about $25 \%$ of the volume; see Harris and Stevens, 1989), this saturation of fura- 2 indicates that $\mathrm{Ca}^{2+}$ increases to very high levels in dendrites as well as in spines.

We observed small AP5-sensitive $\mathrm{Ca}^{2+}$ accumulations in regions not receiving monosynaptic input. Larger accumulations in the absence of AP5 could result from increased influx through VDCCs produced by an enhanced membrane depolarization when NMDA receptor-mediated currents are present. Alternatively, activation of NMDA receptor channels by ambient glutamate (Sah et al., 1989) could contribute to the accumulations.

AP5-insensitive accumulations. Why are AP5-insensitive calcium accumulations in the soma and distal-dendritic regions much smaller than accumulations in proximal-apical and basal dendrites? Differences between calcium accumulations in the soma and the proximal dendrites could be accounted for either by differences in the surface area-to-volume ratio for the soma and the dendrites, or by a lower density of VDCC on the soma. When comparing two structures with different sizes, such as the soma and a dendrite, it is difficult to draw conclusions about the relative channel density based solely upon calcium accumulations when the properties of intrinsic $\mathrm{Ca}^{2+}$ buffers and pumps are not known. If we make simplifying assumptions and ignore calcium buffering and pumping, then for a uniform VDCC distribution calcium accumulations would scale as the surface area-to-volume ratio and accumulations would be about 10 fold larger in dendrites than in the soma. Differences of fourto fivefold were observed. Therefore, it is premature to ascribe the smaller calcium accumulations observed in the soma to a lower VDCC density in the soma compared to the proximal dendrites. In light of the simplifying assumptions made, it is not possible to correct for the surface-to-volume ratios and determine the relative channel densities from the observed accumulations.

In dendritic regions, where surfacc arca-to-volume ratios arc similar, it is possible to draw conclusions about the source of the inhomogeneous calcium accumulations we observe. Since most of the AP5-insensitive accumulations appear to be due to influx through VDCC, the distribution of accumulations could represent a spatial pattern of depolarization experienced by these channels or a difference in spatial distribution of VDCC. Consider first the possibility that there is a difference in depolarization for VDCC within different regions of the cells. It is unlikely that these different stimulus conditions (Fig. 10) could stimulate excitatory inputs that would produce this characteristic pattern of accumulation for three reasons: (1) region CA3 was removed in most experiments, (2) recurrent excitation is 
probably not a prominent feature of CAl circuitry (Knowles and Schwartzkroin, 1981) as it is in CA3, and (3) similar accumulations were observed with both intracellular depolarization (Regehr et al., 1989) and antidromic stimulation. For stimulation of inputs in stratum moleculare, the largest depolarization produced by passive conductance would be in stratum moleculare yet the largest calcium accumulations are observed in the proximal dendrites. Therefore, a uniform VDCC distribution and depolarization provided by passive propagation of synaptic potentials could not account for the observed $\left[\mathrm{Ca}^{2+}\right]_{i}$ distribution.

It is possible that active $\mathrm{Na}^{+}$conductances could contribute to localized accumulations. Intradendritic recordings (Wong and Prince, 1978, 1979) and simulations describing such recordings (Traub and Miles, 1991) suggest that sodium channel density is highest near the soma. If the depolarization generated by an action potential near the soma were propagated passively in the dendrites, it would decay about threefold in one length constant (estimated to be $300 \mu \mathrm{m}$ ). Due to the nonlinear current-voltage relation for L-type $\mathrm{Ca}^{2+}$ channels, a difference of only $10 \mathrm{mV}$ would result in a threefold reduction in $\mathrm{Ca}^{2+}$ influx (Kay and Wong, 1987). We directly tested the involvement of sodium channels in AP5-insensitive calcium accumulations by blocking sodium channels with QX-314 and conclude that sodium channel activation contributes significantly to the AP5-insensitive accumulations by depolarizing VDCCs in cellular regions distant from the site of synaptic input.

Can spike invasion, possibly influenced by $\mathrm{Na}$ channel distribution account for the pattern of AP5-insensitive calcium accumulation such as that shown in Fig. 12? Does a decrease in the density of VDCC along the apical dendrite contribute to this spatial pattern? Two results suggest that spike invasion via $\mathrm{Na}$ channel activation could contribute to this spatial profile. First, measurements with the Na-sensitive fluorophore SBFI (Minta and Tsien, 1989) indicate that the spatial pattern of accumulation for $\mathrm{Na}$ is similar to that of AP5-insensitive calcium accumulations, $\mathrm{Na}$ peaks in proximal dendrites and decays to lower levels in distal dendrites (Tank and Regehr, 1989 abstract; Jaffe et al., 1991 abstract). Second, in the presence of QX-314 differences between AP5-insensitive accumulations in proximal and distal dendritic regions are much less pronounced than in control cells and in some cases were virtually eliminated (see Fig. 8 and Table 1). Although it appears that calcium channels are present in all dendritic regions of a hippocampal pyramidal cell (Regehr and Tank, 1989; see also Fig. 11, Ca) a decreased density of calcium channels along the apical dendrite could contribute to the spatial pattern of accumulation. Consider the AP5-insensitive accumulations observed with QX-314 inside the cell (Fig. 8 and Table 1). In many cases accumulations in proximal dendrites were larger than in distal dendrites, even when synaptic inputs to distal dendrites were activated; this was particularly true for $20 \mathrm{~Hz}$ stimulation. However, for $100 \mathrm{~Hz}$ stimulation the spatial differences between proximal and distal dendrites were sometimes not apparent. In addition it should be emphasized that QX-314 is far from being an "intracellular TTX." It blocks sodium channels in a use-dependent manner, and at sufficiently high concentrations it can begin to affect potassium conductances. It is likely, though, that during tetanic stimulation after the first several stimuli QX-314 would provide an effective $\mathrm{Na}$ channel block. Clearly more experiments are rcquircd to determine the relative contribution of VDCC density and spike invasion to the AP5-insensitive calcium accumulations.
We conclude that differences between accumulations in proximal and distal dendrites are produced, at least in part, by a higher VDCC density in the proximal dendrites. In support of this conclusion, antibodies to the dihydropyridine-binding calcium channels have been reported to be localized to the soma and proximal dendrites of CAl pyramidal cells (Westenbroek et al., 1990).

\section{Microfluorometric measurement of ionic concentrations in intact tissue}

A number of artifacts can compromise fluorescence measurements of ionic concentrations in intact tissues, and care must be exercised to avoid problems. Here, we discuss several sources of potential problems that we have had to deal with in the course of the experiments reported in this article.

Changes in brain slice background fluorescence, produced for example by changes in NADH levels in response to neural activation, can produce errors in the optical measurements of ionic levels. In our experiments, it was necessary to ascertain the stability of the background fluorescence and to determine the magnitude of activity-dependent changes in background fluorescence. In area $\mathrm{CAl}$ of the guinea pig hippocampus, artifacts produced by changes in background fluorescence were typically quite small (see Materials and Methods). However, it is vital to check the contributions of these effects to fluorescence measurements under the exact experimental conditions used, and there is no reason to assume that the stability and the activity dependence of the background fluorescence intensity will be acceptable for a wide variety of experiments. We have observed that background fluorescence changes in neocortical slices produced by low concentrations of bath-applied neurotransmitters such as NMDA can be large enough to compromise severely fura-2 measurements of calcium transients in pyramidal neurons (R. Yuste, K. R. Delaney, and D. W. Tank, unpublished observations).

The appropriate concentration ranges and ionic selectivity of the indicator molecule must also be considered. For example, measurements with furaptra suggest that fura- 2 may underestimate calcium levels in dendritic regions receiving high-frequency synaptic input. This is a consequence of attempting to measure large transients quantitatively with a high-affinity indicator. Although furaptra has a lower affinity for calcium and is more appropriate for measuring micromolar changes, its ionic selectivity is not optimized for calcium measurements when magnesium ions are present. It is possible that furaptra fluorescence changes may actually reflect magnesium transients, rather than calcium transients. In general, the ionic selectivity of a fluorophore may have to be taken into account in attempting measurements of the type reported here.

Attempts to improve the spatiotemporal resolution of calcium imaging, such as measuring calcium transients in spines in response to a brief tetani, will demand increased signal-to-noise ratio. However, caution must be exercised in attempting to improve the signal-to-noise ratio by using either very high illumination intensities or high concentrations of exogenously introduced calcium fluorophore. We have observed that illumination at extremely high intensities can produce artifactual increases in cytoplasmic calcium through photodamage. Such increases can be local or widespread. In many cases, photoinduced calcium increases eventually recover to resting levels. A different problcm is that cxogenous calcium buffers can affect both the amplitude and the time course of synaptically evoked calcium transients. This is well illustrated by our experiments 
(Fig. 6) in which high levels of the extrinsic buffer fura-2 were purposefully introduced into the cytoplasm. The time course of calcium decay was substantially lengthened. The explicit dependence of calcium buildup and decay kinetics on added extrinsic buffer concentration has recently been mathematically modeled and explored in experiments measuring calcium accumulations in presynaptic terminals (Tank, Delaney, and Regehr, unpublished observations). It should also be noted that in the high fura- 2 cases we have described here, there seemed to be a somewhat larger reduction in the AP5-sensitive component than in the AP5-insensitive component. This observation certainly warrants further investigation and clearly indicates that the effects of high fura- 2 concentrations can be insidious. These experiments illustrate the need to be careful not to distort calcium transients excessively by adding large amounts of calcium fluorophore to a cell if the goal is to determine "natural" calcium responses. The sensitivity of each cell type to overloading with fura-2 will depend on the dissociation constants, concentrations, and kinetic properties of its intrinsic buffers (Tank, Delaney, and Regehr, unpublished observations), and hippocampal pyramidal cells seem rather sensitive in this regard. In addition, caution is suggested in attempting to use whole-cell electrodes to fill cells with optical indicators. In such experiments, endogenous buffers may be replaced by exogenous buffers in the electrode and cell calcium dynamics are likely to have been altered.

With careful attention to the issues described above, the imaging methods described in this article can be extended to the measurement of the intracellular concentration of other ions in neurons contained within brain slices. For example, it is possible to measure intracellular sodium concentration using SBFI (Minta and Tsien, 1989; Regehr and Tank, unpublished observations). The techniques could be applied to a large number of other fluorophores now available (as reviewed in Tsien, 1988).

Note added in proof. Since the submission of this article, two reports have appeared which conclude that there are separate pools of $\mathrm{Ca}^{2+}$ in spines and dendrites (Guthrie et al., 1991; Muller and Connor, 1991). In the important study by Muller and Connor, synaptically activated localized AP5-sensitive $\mathrm{Ca}^{2+}$ increases were observed that were thought to occur in spines. Although the relatively high fura-2 levels used in these studies undoubtedly reduced peak $\mathrm{Ca}^{2+}$ accumulations, it is unlikely that this would greatly alter the basic observation of separate $\mathrm{Ca}^{2+}$ pools. Several cautions detailed in the Discussion may be relevant to the report of sustained calcium levels in spines. In regard to the article by Guthrie et al., our findings suggest that the $\mathrm{Ca}^{2+}$ wave produced by photodamage departs significantly from normal physiological conditions in hippocampal pyramidal cell dendrites. It is difficult to relate findings based on such extreme conditions to our measurements of $\mathrm{Ca}^{2+}$, which were designed to measure $\mathrm{Ca}^{2+}$ increases that occur during synaptic transmission.

Note added in proof. Jaffe and colleagues (Jaffe et al., 1992) have recently confirmed our original observations (Regehr et al., 1989) that calcium accumulations produced by influx through VDCC decline with distance along the apical dendrite, but are still observed, although reduced in amplitude, in far distal dendrites. They also show that SBFI-measured $\mathrm{Na}$ accumulations in hippocampal pyramidal cells (Tank and Regehr, 1989) show a peaked distribution, with the largest changes occurring in proximal dendrites. However, from the dependence of calcium accumulation on $\mathrm{Na}$ spiking they conclude that the decline in calcium accumulation with distance along the apical dendrite is entirely determined by the $\mathrm{Na}$ channel distribution and $\mathrm{Na}$ spike invasion, and that a reduced $\mathrm{Ca}$ channel density in distal dendrites docs not contributc. The QX-314 results we have presented here also support the idea that $\mathrm{Na}$ channel activation contributes substantially to the amount of influx produced through VDCC. However, both the data we present here and the data they have reported are still consistent with a reduced density of VDCC in distal dendrites. For example, even under conditions of TEA-produced enhancement of calcium spiking (cf. Figure $2 a, b$; Jaffe et al., 1992), a 7-fold lower level of calcium accumulation is observed in far distal dendrites (130 $\mathrm{nm}$ at 400 microns) compared to more proximal dendrites $(\sim 900 \mathrm{nM}$ at 270 microns). Further experiments are required to clarify if the residual decay in accumulation with distance along the apical dendrite is produced by electrotonic decay of depolarization or reduced channel density.

\section{References}

Adams PR, Constanti A, Brown DA, Clark RB (1982) Intracellular $\mathrm{Ca}^{++}$activates a fast voltage-sensitive $\mathrm{K}^{+}$current in vertebrate sympathetic neurones. Nature 296:746-749.

Allen TJA, Noble D, Reuter H (1989) Sodium-calcium exchange. New York: Oxford UP.

Aniksztejn L, Ben-Ari Y (1991) Novel form of long term potentiation produced by $\mathrm{K}^{+}$channel blocker in the hippocampus. Nature 349: 67-69.

Barrionuevo G, Brown TH (1983) Associative long-term potentiation in hippocampal slices. Proc Natl Acad Sci USA 80:7347-7351.

Bean BP (1989) Classes of calcium channels in vertebrate cells. Annu Rev Physiol 51:367-384.

Bernardo LS, Musukawa LM, Prince DA (1982) Electrophysiology of isolated hippocampal pyramidal dendrites. J Neurosci 2:1614-1622.

Berridge MJ, Irvine RF (1984) Inositol trisphosphate, a novel second messenger in cellular transduction. Nature 312:315-321.

Bliss, TVP, Gardner-Medwin AR (1973) Long-lasting potentiation of synaptic transmission in the dentate area of the unanaesthetized rabbit following stimulation of the perforant path. J Physiol (Lond) 232: 357-374.

Bliss TVP, Lomo T (1973) Long-lasting potentiation of synaptic transmission in the dentate area of the anaesthetized rabbit following stimulation of the perforant path. J Physiol (Lond) 232:331-356.

Brown DA, Griffith WH (1983) Persistent slow inward calcium current in voltage-clamped hippocampal neurones of the guinea-pig. J Physiol (Lond) 337:303-320.

Brown TH, Chapman PF, Kairiss EW, Keenan CL (1988) Long-term synaptic potentiation. Science 242:724-728.

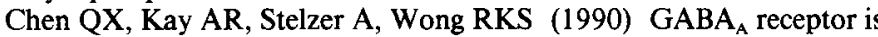
regulated by phosphorylation in acutely dissociated guinea-pig hippocampal neurones. J Physiol (Lond) 420:207.

Choi DW (1988) Calcium-mediated neurotoxicity: relationship to specific channel types and role in ischemic damage. Trends Neurosci 11 : $465-469$.

Collingridge GL, Kehl SJ, McLennan H (1983) The antagonism of amino acid-induced excitations of rat hippocampal CA1 neurones in vitro. J Physiol (Lond) 334:19-31.

Connor JA, Wadman WJ, Hockberger PE, Wong RKS (1988) Sustained dendritic gradients of $\mathrm{Ca}^{2+}$ induced by excitatory amino acids in CA1 hippocampal neurons. Science 240:649-653.

Eckert R, Chad JE (1984) Inactivation of calcium channels. Prog Biophys Mol Biol 44:215-267.

Fisher RE, Gray R, Johnston D (1990) Properties and distribution of single voltage-gated calcium channels in adult hippocampal neurons. J Neurophysiol 64:91-104.

Gahwiler BH, Brown DA (1987) Effects of dihydropyridines on calcium currents in CA3 pyramidal cells in slice cultures of rat hippocampus. Neuroscience 20:731-738.

Gamble E, Koch C (1987) The dynamics of free calcium in dendritic spines in response to repetitive synaptic input. Science 236:13111315.

Grover LM, Teyler TJ (1990) Two components of long term poten- 
tiation induced by different patterns of afferent activation. Nature $347: 477-479$.

Grynkiewicz G, Poenie M, Tsien RY (1985) A new generation of $\mathrm{Ca}^{2+}$ indicators with greatly improved fluorescence properties. J Biol Chem 260:3440-3450.

Guthrie PB, Segal M, Kater SB (1991) Independent regulation of calcium revealed by imaging dendritic spines. Nature 354:76-80.

Harris KM, Stevens JK (1989) Dendritic spines of CA1 pyramidal cells in the rat hippocampus: serial electron microscopy with reference to their biophysical characteristics. J Neurosci 9:2982-2997.

Hockberger PE, Tseng H-Y, Conner JA (1989) Fura-2 measurements of cultured rat Purkinje neurons show dendritic localization of $\mathrm{Ca}^{2+}$ influx. J Neurosci 9:2272-2284.

Holmes WR, Levy WB (1990) Insights into associative long-term potentiation from computational models of NMDA receptor-mediated calcium influx and intracellular calcium concentration changes. J Neurophysiol 63:1148-1168.

Honore T, Davies SN, Drejer J, Fletcher EJ, Jacobsen P, Lodge D, Nielsen FE (1988) Quinoxalinediones: potent competitive nonNMDA glutamate receptor antagonists. Science 241:701-703.

Iino M, Ozawa S, Tsuzuki K (1990) Permiation of calcium through excitatory amino acid receptor channels in cultured rat hippocampal neurones. J Physiol (Lond) 424:151-165.

Jaffe DB Ross WN, Johnston D (1991) The distribution of dendritic calcium entry produced by action potentials in a model hippocampal CA3 neuron. Soc Neurosci Abstr 17:581.

Jaffe DB, Johnston D, Lasser-Ross N, Lisman JE, Mikyakawa H, Ross WN (1992) The spread of $\mathrm{Na}^{+}$spikes determines the pattern of dendritic $\mathrm{Ca}^{2+}$ entry into hippocampal neurons. Nature 357:244-246.

Kay AR (1991) Inactivation kinetics of calcium current of acutely dissociated CAl pyramidal cells of the mature guinea-pig hippocampus. J Physiol (Lond) 437:27-48

Kay AR, Wong RKS (1987) Calcium current activation kinetics in isolated pyramidal cells of the CAl region of the mature guinea-pig hippocampus. J Physiol (Lond) 392:603-616.

Knowles WD, Schwartzkroin PA (1981) Local circuit synaptic interactions in hippocampal brain slices. $J$ Neurosci 1:318-322.

Konishi M, Hollingworth S, Harkins AB, Baylor SM (1991) Myoplasmic calcium transients in intact frog skeletal muscle fibers monitored with the fluorescent indicator furaptra. J Gen Physiol 97:271-301.

Kudo Y, Ogura A (1986) Glutamate-induced increase in intraccllular $\mathrm{Ca}^{++}$concentration in isolated hippocampal neurons. Br J Pharmacol 89:191-198.

Lancaster B, Nicoll RA (1987) Properties of two calcium-activated hyperpolarizations in rat hippocampal neurones. J Physiol (Lond) 389:187-203.

Langer GA (1980) The role of calcium in the control of myocardial contractility: an update. J Mol Cell Cardiol 12:231.

Leblanc N, Hume JR (1990) Sodium current-induced release of calcium from cardiac sarcoplasmic reticulum. Science 248:372-376.

Lipscombe D, Madison DV, Poenie M, Reuter H, Tsien RY, Tsien RW (1988) Spatial distribution of calcium channels and cytosolic calcium channels in growth cones and cell bodies of sympathetic neurons. Proc Natl Acad Sci USA 85:2398-2402.

Lisman J (1989) A mechanism for the Hebb and anti-Hebb processes underlying learning and memory. Proc Natl Acad Sci USA 86:95749578.

Lynch G, Larson J, Kelso S, Barrionuevo G, Schottler F (1983) Intracellular injections of EGTA block induction of hippocampal longterm potentiation. Nature 305:719-721.

MacDermott AB, Mayer ML, Westbrook GL, Smith SJ, Barker JL (1986) NMDA-receptor activation increases cytoplasmic calcium concentration in spinal cord neurones. Nature 321:519-522.

Madison DV, Malenka RC, Nicoll RA (1991) Mechanisms underlying long-term potentiation of synaptic transmission. Annu Rev Neurosci 14:379-397.

Malenka RC (1990) Factors controlling the time course of synaptic potentiation in area CAl of the hippocampus. Soc Neurosci Abstr $16: 274.3$

Malenka RC, Kauer JA, Zucker RS, Nicoll RA (1988) Postsynaptic calcium is sufficient for potentiation of hippocampal slice transmission. Science 242:81-84.

Malenka RC, Kauer JA, Perkel DJ, Nicoll RA (1989) The impact of postsynaptic calcium on synaptic transmission-its role in long term potentiation. Trends Neurosci 12:444-450.
Minta A, Tsien RY (1989) Fluorescence indicators for cytosolic sodium. J Biol Chem 244:32.

Morgan JL, Curran T (1991) Stimulus-transcription coupling in the nervous system: involvement of the inducible proto-oncogenes fos and jun. Annu Rev Neurosci 14:421-451.

Müller W, Connor JA (1991) Dendritic spines as individual neuronal compartments for synaptic $\mathrm{Ca}^{2+}$ responses. Nature 354:73-76.

Nicoll RA, Kauer JA, Malenka RC (1988) The current excitement in long term potentiation. Neuron 1:97-103.

Noble D (1980) Mechanism of action of therapeutic levels of cardiac glycosides. Cardiovasc Res 14:495

Ogura A, Iijima T, Amano T, Kudo Y (1987) Optical monitoring of excitatory synaptic activity between cultured hippocampal neurons by a multi-site $\mathrm{Ca}^{2+}$ fluorometry. 78:69-74.

Partridge LD, Swandula D (1988) Calcium-activated non-specific cation channels. Trends Neurosci 11:69-72.

Perkel DJ, Nicoll RA (1991) The role of protein kinase activity in long-term potentiation. In: Long-term potentiation: a debate of current issues (Baudry M, Davis J, eds). Cambridge, MA: MIT Press.

Poenie M, Alderton J, Steinhardt R, Tsien R (1986) Calcium rises abruptly and briefly throughout the cell at the onset of anaphase. Science 233:886-889.

Raju B, Murphy E, Levy LA, Hall RD, London RE (1989) A fluorescent indicator for measuring cytosolic free magnesium. Am J Physiol 256:C540-C547.

Regan LJ, Sah DWY, Bean BP (1991) $\mathrm{Ca}^{++}$channels in rat central and peripheral neurons: high threshold current resistant to dihydropyridine blockers and $\omega$-conotoxin. Neuron 6:269-280.

Regehr WG, Tank DW (1990a) Postsynaptic NMDA receptor-mediated calcium accumulation in hippocampal CA1 pyramidal cell dendrites. 345:807-810.

Regehr WG, Tank DW (1990b) Characterization of calcium accumulation in hippocampal pyramidal cells. Soc Neurosci Abstr 16 : 491.

Regehr WG, Connor JA, Tank DW (1989) Optical imaging of calcium accumulation in hippocampal pyramidal cells during synaptic activation. Nature 341:533-536.

Sah P, Hestrin S, Nicoll RA (1989) Tonic activation of NMDA receptors by ambient glutamate enhances excitability of neurons. Science 246:815-818.

Sala F, Hernandez-Cruz A (1990) Calcium diffusion modeling in a spherical neuron. Biophys J 57:313-324.

Scharfman HE, Schwartzkroin PA (1989) Protection of dentate hilar cells from prolonged stimulation by intracellular calcium chelation. Science 246:257-260.

Schwartzkroin PA (1975) Characteristics of CA1 neurons recorded intracellularly in the hippocampal in vitro slice preparation. Brain Res 85:423-436.

Schwartzkroin PA, Prince DA (1978) Cellular and field potential properties of epileptogenic hippocampal slices. Brain Res 147:117-130.

Schwartzkroin PA, Slawsky M (1977) Probable calcium spikes in hippocampal neurons. Brain Res 135:157-161.

Stelzer A, Kay AR, Wong RKS (1988) GABA $_{A}$-receptor function in hippocampal cells is maintained by phosphorylation factors. Science 241:339-341.

Sugiyama H, Ito I, Hirono C (1987) A new type of glutamate receptor linked to inositol phospholipid metabolism. 325:531-536.

Tank, DW, Sugimori M, Connor JA, Llinas RR (1988) Spatially resolved calcium dynamics of mammalian Purkinje cells in cerebellar slice. Science 242:773-777.

Tank DW, Regehr WG (1989) Optical imaging of ion concentration dynamics in pyramidal cells in hippocampal brain slice. Soc Neurosci Abstr 15:398.

Traub RD, Llinas R (1979) Hippocampal pyramidal cells: significance of dendritic ionic conductances for neuronal function and epileptogenesis. J Neurophysiol 42:476-496.

Traub RD, Miles R (1991) Neuronal networks of the hippocampus. Cambridge: Cambridge UP.

Wadman WJ, I Ieinemann U, Konnerth A, Neuhaus S (1985) Hippocampal slices of kindled rats reveal calcium involvement in epileptogenesis. Exp Brain Res 57:404-407.

Westenbroek RE, Ahlijanian MK, Catterall WA (1990) Clustering of L-type $\mathrm{Ca}^{2+}$ channels at the base of major dendrites in hippocampal pyramidal cells. Nature 347:281-284.

Williamson A, Alger BE (1990) Characterization of an early after- 
hyperpolarization after a brief train of action potentials in rat hippocampal neurons in vitro. J Neurophysiol 63:72-81.

Wong RKS, Prince DA (1978) Participation of calcium spikes during intrinsic burst firing in hippocampal neurons. Brain Res 159:385390.

Wong RKS, Prince DA (1979) Dendritic mechanisms underlying penicillin-induced epileptiform activity. Science 204:1228-1231.

Wong RKS, Prince DA, Basbaum AI (1979) Intradendritic recordings from hippocampal neurons. Proc Natl Acad Sci USA 76:986-990.

Yaari Y, Hamon B, Lux HD (1987) Development of two types of calcium channels in cultured mammalian hippocampal neurons. Science 235:680-682.
Yamada WM, Koch C, Adams PR (1989) Multiple channels and calcium dynamics. In: Methods in neuronal modelling: from synapses to networks. Cambridge, MA: MIT Press.

Yamamoto C (1972) Activation of hippocampal neurons by mossy fiber stimulation in thin brain sections in vitro. Exp Brain Res 14: 423-435.

Yuste R, Katz LC (1989) Transmitter-induced changes in intracellular free calcium in brain slice of developing neocortex. Soc Neurosci Abstr $15: 2$. 